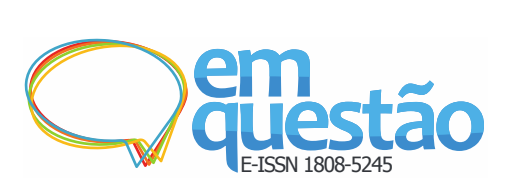

\title{
A construção da atual fundamentação do pensamento biblioteconômico-informacional nos cursos de graduação em Biblioteconomia no Brasil
}

\author{
Priscila de Souza Figueira Cervo \\ Graduada; Universidade Federal do Estado do Rio de Janeiro, Rio de Janeiro, RJ, Brasil; \\ priscilasrj@hotmail.co \\ Gustavo Silva Saldanha \\ Doutor; Instituto Brasileiro de Informação em Ciência e Tecnologia, Rio de Janeiro, RJ, Brasil; \\ Universidade Federal do Estado do Rio de Janeiro, Rio de Janeiro, RJ, Brasil;
}

gustavosaldanha@ibict.br

\begin{abstract}
Resumo: O trabalho discutiu a epistemologia biblioteconômico-informacional no Brasil a partir de uma perspectiva documental estruturada na análise de matrizes curriculares, ementas e planos de estudo. O objetivo geral foi compreender a construção dos fundamentos teóricos do campo, tendo como ponto de partida as disciplinas voltadas para a fundamentação dos cursos brasileiros de graduação. Como objetivos específicos, almejou-se: a. discutir a condição quali e quantitativa da fundamentação em Biblioteconomia \& Ciência da Informação no Brasil hoje; b. identificar os conceitos centrais da fundamentação biblioteconômico-informacional a partir de ementas; c. mapear as autoridades bibliográficas presentes em tal fundamentação a partir das referências bibliográficas dos planos de estudos; $d$. mapear as fontes bibliográficas centrais a partir dos planos de estudos. A pesquisa, de natureza teórica, baseada em fontes documentais, atravessou as seguintes etapas metodológicas: em primeiro lugar, coleta documental nos portais eletrônicos em rede das universidades e por solicitações diretas; em segundo lugar, análise e discussão dos dados via esquemas comparativos, estabelecidos a partir variáveis constituídas no diálogo entre o referencial teórico e as características das fontes. Os resultados demonstraram a atual heterogeneidade dos processos de teorização biblioteconômico-informacional no país, além de identificar a correlação assertiva com as hipóteses de aprofundamentos epistemológicos e de expansão do debate teórico no campo.
\end{abstract}

Palavras-chave: Biblioteconomia e Ciência da Informação - Brasil. Epistemologia. Ensino. Estrutura curricular. Fundamentação biblioteconômicoinformacional. 


\section{Introdução}

Tendo como preocupação central a compreensão dos atuais modos de fundamentação no contexto do ensino na graduação em Biblioteconomia e Ciência da Informação (BCI) no Brasil, procuramos no trabalho observar o percurso de operacionalização de tais fundamentos do e no campo. A proposta do estudo foi reconhecer uma compreensão sobre a dinâmica contemporânea de construção da fundamentação biblioteconômico-informacional, ou seja, de uma forma de estruturação de sua epistemologia.

O problema de pesquisa que norteou a investigação foi assim explicitado: como se dá hoje, no Brasil, a fundamentação do pensamento biblioteconômico-informacional no âmbito da graduação? O objetivo geral foi compreender a construção dos fundamentos epistemológicos panorâmicos a partir das matrizes curriculares de graduação do Brasil no escopo da formação biblioteconômico-informacional. Como objetivos específicos, almejamos: a. discutir a condição quali e quantitativa da fundamentação em BCI no Brasil hoje; b. identificar os conceitos centrais da fundamentação biblioteconômicoinformacional a partir de ementas; c. mapear as autoridades bibliográficas presentes em tal fundamentação a partir das referências bibliográficas dos planos de estudo; d. mapear as fontes bibliográficas centrais presentes a partir das referências disponíveis nos planos de estudo.

No quadro teórico, o questionamento de Mostafa (1985) demonstrava já a profusão de problemas que está situada nas construções de uma economia política da epistemologia encontrada na formulação dos estudos informacionais. Suas preocupações estão, em grande medida, repercutidas nos problemas de formulação do campo demonstradas em Shera e Cleveland (1977), bem como, no plano da crítica social, na visão epistemológica e histórica de García Gutiérrez (2011).

No mesmo decurso, o presente estudo demonstrou como os problemas encontrados nos anos 1980 ainda se multiplicam e a indeterminação pode ser reconhecida a partir de diferentes variáveis. Não demarcamos, porém, como problemática, a amplitude de ideias e a virtualidade da construção do 
pensamento. O que abordamos como marcas aporéticas está vinculado ao uso desdobrado de terminologias ancoradas na ausência de conceitos, fundamentações filosóficas e epistemológicas, que parecem se multiplicar no território nacional a partir da guerra de nomenclaturas dos anos 1950 e 1960 nos Estados Unidos, marcada pelo uso da noção information.

Para esse passo da reflexão, a opção pelo extrato de um universo da fundamentação na graduação se deu exatamente para reconhecer um plano de aproximação com a construção histórica do campo, dada a partir da prática em bibliotecas, formações técnicas, associações profissionais, até chegarmos à consolidação de instituições de pesquisa e de formação científica (do Instituto Brasileiro de Bibliografia e Documentação (IBBD) aos programas de pósgraduação nos anos 1970; estes, diretamente vinculados ao elemento inicial, ou seja, à prática em bibliotecas, tomadas como um laboratório do pensamento biblioteconômico-informacional ontem e hoje).

Lembramos, por fim, que a opção pela expressão "fundamentação biblioteconômico-informacional" está baseada na perspectiva terminológica de credenciamento de cursos de graduação e pós-graduação dos Estados Unidos da América, American Library Association (ALA), repercutida em diferentes contextos no plano internacional, principalmente na influência teórica e curricular. Esse é o caso da formação brasileira, foco de nosso corpus, comprovado pela literatura epistemológico-histórica do campo, bem como pelos resultados (no plano terminológico) do próprio estudo aqui apresentado.

\section{Uma breve contextualização histórico-institucional}

As dificuldades de demarcação espaço-temporal do campo estão na pauta comum dos discursos epistemológicos dos anos 1950 e 1960, concentrados em uma discursividade anglo-americana ecoada mundialmente. No mesmo contexto, propaga-se no âmbito internacional, por sua vez, o pensamento de Paul Otlet (1934), principalmente a partir dos aportes da Unesco e sua promoção ao avanço científico-tecnológico de países subdesenvolvidos. 
As duas linhas de fundamentação "colonizadoras" no plano mundial (uma, anglófona, centrada nas relações terminológicas entre os termos library e information, e a outra, francófona, sustentada pelas noções document e documentation) provocarão grande impacto na formação e no pensamento brasileiro no então espaço-tempo biblioteconômico-informacional em desenvolvimento. Os cenários locais de formação e de pesquisa (em seus primórdios) recebem, pois, as configurações de tais influências, como relacionado por Shera e Cleveland (1977), Pinheiro e Loureiro (1995) e por Silva e Ribeiro (2002).

Como ocorrido nas diferentes tradições institucionais, os cursos de formação no âmbito técnico e no âmbito do ensino superior (em seus contextos de graduação e pós-graduação lato sensu) no Brasil, entre os anos 1950 e 1960, começam a adotar em suas nomenclaturas os termos "informação" e “documentação", e a primeira pós-graduação do campo, tecida sob o IBBD, substituirá a noção de "pesquisa bibliográfica" por "documentação científica". O percurso comparativo-internacional de Fonseca (1979) mapeia o curso contínuo de tais etapas "colonizadoras" e suas mudanças.

O desdobramento das transformações de nomenclaturas é identificado ainda nas análises históricas de Fonseca (1987, 2007), Castro (2000), Russo (2010), Pinheiro \& Loureiro (1995). As influências teóricas, por sua vez, ligadas diretamente às abordagens, aos conceitos e aos métodos que procuravam estabelecer outros espaços de afirmação discursiva no campo até os anos 1960, foram relacionadas por Andrade e Metchko (1981), Miranda (2003), Mostafa (1983), Mueller (1985), Silva e Ribeiro (2002), Oddone (2006), Souza (1996, 1995, 1993).

A marca epistemológica de fundamentação dos saberes, no âmbito da graduação e da pós-graduação até ali desenvolvida na modalidade lato sensu no IBBD (ODDONE, 2006), se fazia, em grande parte, ausente. Desse modo, as argumentações epistemológicas para as adoções terminológicas eram frágeis em diferentes aspectos, podendo, no entanto, ser resumidas em dois grandes eixos, segundo as análises acima mapeadas: o historiográfico e o epistemológico. No 
primeiro, sabe-se que até ali (anos 1960) inexiste uma discussão sobre "como se fazer história de uma prática", de uma formação e de um pensamento biblioteconômico-informacional no contexto nacional, elementos teóricos de fundo historiográficos atentados como centrais para pensar a formação do pensamento no campo, segundo Couzinet (2009).

No segundo cenário, do mesmo modo, a discussão epistemológica é limitada ou inexistente: a pergunta sobre uma teoria do conhecimento naquilo que se configurava nos Estados Unidos sob a expressão library and information science (SHERA; CLEVELAND, 1977) é pouco cultivada. A pesquisa teórica é ainda incipiente e se estabelece sem o auxílio dos complexos de pós-graduação que estão por se desenvolver no Brasil, ao mesmo tempo em que a empiria demarcada como espírito do saber tendia a tomar a aplicação como resposta imediata à reflexão ausente.

Nesse cenário, a dificuldade de definir o campo até ali já lançada tornase ainda maior quando da profusão de nomenclaturas e de abordagens que, não apenas sob aproximações aplicadas e/ou teóricas, adentram o campo como categorias disciplinares substitutas ou integradoras. $\mathrm{O}$ desenvolvimento intenso da pós-graduação stricto sensu a partir dos anos 1970 no cenário internacional, incluindo o território brasileiro, não altera imediatamente o problema de fundamentação e o vazio epistemológico, como discutido, no cenário internacional, ao final da década, pela tetralogia de Brookes (1980a, 1980b, 1980c, 1981).

Em paralelo à questão epistemológica aberta, como demonstram García Gutiérrez (2011) e Mostafa (1985), tentativas de teorias gerais para responder pelas práticas de organização, preservação e acesso ao conhecimento registrado em bibliotecas e instituições afins se aproximam no Brasil, oriundas de tradições estrangeiras, principalmente advindas das tentativas de definir uma ciência nova, distinta e interdisciplinar, sob a noção específica information science, afastadas (tais teorias) dos dilemas latino-americanos, postulando epistemologias hegemônicas que ora transversalizam, ora verticalizam os posicionamentos no país. 
Desenvolvem-se, entre os anos 1970 e 1980, paralelamente, a graduação e a pós-graduação no campo no território brasileiro, levando à fundação da então Associação Nacional de Pesquisa e Pós-Graduação em Ciência da Informação e Biblioteconomia (ANCIB), criada por pós-graduações que levavam, majoritariamente, a nomenclatura "biblioteconomia" como significante central para a determinação da epistemologia do campo. O uso inicial desta nomenclatura da ANCIB conjuga, politicamente, a noção aplicada intensamente nos programas de undergraduate e graduate nos Estados Unidos, ou seja, a expressão library and information science. No entanto, ainda sob a influência intensiva estadunidense, nos anos 1990, os programas de pósgraduação, no Brasil, alteram suas nomenclaturas para a noção information science.

A mutação terminológica dos cursos de graduação, do mesmo modo, ganha configurações distintas, adentra o século corrente sob elaborações discursivas como "biblioteconomia e documentação", "biblioteconomia e gestão da informação", impactando nas disciplinas de fundamentação tanto da graduação quanto da pós-graduação. A complexidade da demarcação epistemológica refletida pela terminologia macroteórica se amplia, ainda, com a criação dos cursos de graduação em Arquivologia e Museologia em espaços institucionais, como escolas e institutos históricos de Biblioteconomia, com cinquenta ou mais anos de desenvolvimento, como é o caso da Universidade Federal de Minas Gerais.

Dado esse percurso histórico, a partir do ponto de partida dessas influências e mutações, retomamos nossa questão de pesquisa: como se dá hoje, no Brasil, a fundamentação do pensamento biblioteconômico-informacional no âmbito da graduação?

A curiosidade epistêmica que nos orientou esteve ligada, desde o primeiro momento, à preocupação de problematizar, para além da pósgraduação, o modo como, na atualidade, têm repercutido as transformações do percurso histórico que apresentam, no Brasil, sob a institucionalidade da Biblioteconomia, representada por escolas, institutos, departamentos e seus 
quadros docentes, uma relação direta com o desenvolvimento do campo. A justificação aqui inclui o IBBD, responsável pela primeira pós-graduação do campo, desenvolvida sob a perspectiva teórico-profissional da bibliotecária Lygia Queiroz Sambaqui, como demonstrou Oddone (2006), a partir da prática profissional.

\section{Procedimentos metodológicos: do desafio da pesquisa documental nos estudos epistemológicos}

O estudo trata-se de uma pesquisa documental, baseada na identificação, seleção e análise de matrizes curriculares, ementas e planos de estudo. A partir do reconhecimento de matrizes curriculares, a pesquisa selecionou disciplinas de fundo teórico, incluindo as disciplinas de "fundamentação direta" (ou seja, de Fundamentos da Biblioteconomia e Ciência da Informação) e outras, que apresentavam elementos de fundamentação de saberes afins incluídos a partir dos projetos pedagógicos.

Após o reconhecimento das matrizes e de seus componentes, seguimos para a análise das ementas das disciplinas e seus planos de estudo. Foram extraídos do corpus analítico constituído os seguintes dados: o número geral de disciplinas de fundamentação encontradas em cada matriz em relação à totalidade de disciplinas da matriz; conceitos das ementas; conceitos dos planos de estudo; autores dos planos de estudo; fontes dos planos de estudo. A partir dessas variáveis, constituíram-se as etapas analítica e de discussão.

Sob o auxílio dos principais diretórios institucionais adotados como fontes de informação a respeito das instituições - Associação Brasileira de Educação em Ciência da Informação (ABECIN) e Associação Nacional de Pesquisa e Pós-Graduação em Ciência da Informação (ANCIB) -, constituímos uma listagem dos cursos de graduação em Biblioteconomia.

Todos os dados coletados nos diretórios de pesquisa e nos próprios portais na internet das instituições foram armazenados numa planilha eletrônica. No total, foram selecionados 37 cursos de graduação em Biblioteconomia de 35 
instituições distintas. A inexistência de instituições e de dados documentais de cursos de graduação (atualmente vigentes) no contexto do levantamento (o ano de 2016) e no composto final do corpus foi resultado de três problemas recorrentes:

a) ausência de correlação dos dados da ABECIN e da ANCIB e aqueles das instituições citadas por ambas;

b) ausência de dados atualizados dos cursos de graduação;

c) ausência momentânea (durante o período de coleta) de fontes sobre a graduação por parte das instituições pesquisadas, mesmo quando do contato direto via correio eletrônico e telefone.

Ainda há de se salientar que na relação de escolas, institutos, faculdades e unidades do campo, no Brasil, disponíveis no portal da ABECIN, estavam incluídos os cursos de Arquivologia e Museologia da Universidade Federal do Estado do Rio de Janeiro (UNIRIO), os cursos de Arquivologia da Universidade Federal do Espírito Santo (UFES) e da Universidade Federal de Santa Maria (UFSM). No entanto, tais cursos, para essa etapa da reflexão, não foram incluídos no levantamento.

Justifica-se o critério provisório de exclusão do corpus em razão do ponto de vista epistemológico-histórico que ancora a abordagem analítica contemporânea, bem como em virtude da dificuldade de determinação do ponto de vista de tais configurações diante do problema da epistemologia que se estabeleceu, historicamente, sob as noções de information science e library and information science, nos cenários internacional e nacional. Em outros termos, uma pergunta poderia responder a esse questionamento: em que medida aquilo que se propagou e se desenvolveu sob os macroconceitos "museologia" e "arquivologia" se entrelaça, historicamente, nas lutas epistêmicas, institucionais e políticas das noções information science e library and information science no contexto brasileiro no decurso do século XX, ou seja, na longa trajetória histórica do campo no país? 
Observamos, porém, que foi incluído em nosso corpus o curso de Gestão da Informação da UFPR, presente no diretório ABECIN. A razão está em sua relação histórica vinculada, justamente, a essa luta, ou seja, no caso, ao antigo curso de Biblioteconomia e Documentação. Ainda, lembramos que a expressão "gestão da informação" igualmente veio compor a configuração terminológica de outros cursos de Biblioteconomia, sob a influência das terminologias anteriormente indicadas, bem como de disciplinas da formação biblioteconômico-informacional.

Dentre os cursos mapeados, foram selecionadas as disciplinas que fundamentassem as "marcas disciplinares terminológicas" comuns no campo, a saber, as noções "biblioteconomia”, "documentação", "informação", "ciência da informação", "gestão da informação", e suas múltiplas variações. Para tal, dado o universo (a fundamentação em graduação no campo biblioteconômicoinformacional) e a amostra (a fundamentação do campo em disciplinas específicas na atualidade, no contexto nacional), o corpus foi definido a partir das matrizes identificadas, sendo verticalizado em sua apropriação adotando-se ementas e planos de estudo das disciplinas recuperadas.

Ao todo, obtivemos as matrizes de 33 (trinta e três) cursos, pelo portal na internet das universidades ou por meio de solicitação eletrônica ou telefônica; 24 (vinte e quatro) ementas e 16 (dezesseis) planos de estudo das disciplinas. A possibilidade de adotar os projetos pedagógicos dos cursos para tal compreensão foi planejada, porém abandonada, diante da dificuldade de recuperação dos dados, bem como da ausência de atualização para o período de coleta.

Como mencionado, um ponto relevante reconhecido no percurso de discussão sobre o escopo da fundamentação do campo foi a preocupação em identificar, além das disciplinas orientadas para a fundamentação biblioteconômico-informacional, outras disciplinas de orientação epistemológica em ciências humanas e sociais. O recurso nos permitiu compreender possíveis diretivas de fundamentação como indicadores de tendências epistemológicas. Além disso, no plano estrutural, o olhar sobre essas demais disciplinas (como Introdução à Filosofia, Introdução à Sociologia) nos conduziu à preocupação na 
filosofia da proposta pedagógica de constituir uma base sólida de fundamentação para o campo.

Faz-se necessário, ainda, observar que a noção de "fundamentação" foi aqui constituída (isto é, operacionalizada para o estudo) a partir das tentativas de correlação entre matriz curricular, ementas, planos de estudo, tendo como horizonte não apenas o domínio do significante (o termo "fundamentação"). Orientamo-nos também pelo conjunto de disciplinas que se propõe determinar a expressão geral de um pensamento (comumente reconhecidas pelos termos “fundamentação" e "introdução").

Não foi nosso intuito, no entanto, para essa etapa da pesquisa, adentrar o debate epistemológico sobre o papel, de fato, estruturado em uma filosofia da ciência de cada uma dessas disciplinas (nem na própria definição filosófica do gesto reflexivo do "fundamentar"). Consequentemente, o manejo da documentação do estudo nos permitiu reconhecer as problemáticas existentes nesse aspecto e as lacunas em aberto. Dessa maneira, o caminho da pesquisa documental ao plano teórico atingiu, no estudo, a possibilidade de reconhecimento de um quadro conceitual (permitido pela etapa de análise das ementas e dos planos de estudo).

\section{Resultados}

As matrizes coletadas foram separadas por região e esquematizadas através de quadros e tabelas de modo a permitir a visualização dos dados básicos da instituição e do respectivo curso de graduação. No Quadro 1, identificamos as disciplinas que compõem as matrizes, destacando aquelas que se propõem fundamentar o campo. Representando os nomes dos cursos de Biblioteconomia, os nomes das universidades às quais estão ligadas e a região na qual estão localizadas, o esquema nos permite iniciar as primeiras inferências sobre a complexidade da fundamentação do campo, estruturada na imprecisão terminológica de demarcação dos conceitos disciplinares, ou macronoções que definem a configuração da fundamentação do campo - no entanto, com predominância da noção "biblioteconomia". 
Quadro 1 - Mapeamento das instituições de graduação do território brasileiro

\begin{tabular}{|c|c|c|c|}
\hline REGIÃO & ESTADO & INSTITUIÇÃO & NOME DO CURSO \\
\hline \multirow{15}{*}{ SUDESTE } & \multirow{4}{*}{$\begin{array}{l}\text { RIO DE } \\
\text { JANEIRO }\end{array}$} & $\begin{array}{l}\text { Universidade Federal Fluminense - } \\
\text { UFF }\end{array}$ & $\begin{array}{lr}\text { Bacharelado } & \mathrm{em} \\
\text { Biblioteconomia } & \mathrm{e} \\
\text { Documentação } & \end{array}$ \\
\hline & & $\begin{array}{l}\text { Universidade Federal do Rio de } \\
\text { Janeiro - UFRJ }\end{array}$ & $\begin{array}{l}\text { Bacharelado em } \\
\text { Biblioteconomia e Gestão de } \\
\text { Unidades de Informação }\end{array}$ \\
\hline & & \multirow{2}{*}{$\begin{array}{l}\text { Universidade Federal do Estado do } \\
\text { Rio de Janeiro - UNIRIO }\end{array}$} & $\begin{array}{l}\text { Bacharelado } \\
\text { Biblioteconomia }\end{array}$ \\
\hline & & & $\begin{array}{ll}\text { Licenciatura } & \text { em } \\
\text { Biblioteconomia } & \end{array}$ \\
\hline & \multirow{8}{*}{ SÃO PAULO } & $\begin{array}{l}\text { Faculdades Integradas Coração de } \\
\text { Jesus - FAINC }\end{array}$ & $\begin{array}{ll}\text { Bacharelado } & \mathrm{em} \\
\text { Biblioteconomia } & \end{array}$ \\
\hline & & $\begin{array}{l}\text { Fundação Escola de Sociologia e } \\
\text { Política de São Paulo - FESPSP }\end{array}$ & $\begin{array}{l}\text { Bacharelado em } \\
\text { Biblioteconomia e Ciência } \\
\text { da Informação }\end{array}$ \\
\hline & & $\begin{array}{l}\text { Pontifícia Universidade Católica - } \\
\text { PUC Campinas }\end{array}$ & $\begin{array}{l}\text { Bacharelado } \\
\text { Biblioteconomia }\end{array}$ \\
\hline & & $\begin{array}{l}\text { Centro Universitário Assunção - } \\
\text { UNIFAI }\end{array}$ & $\begin{array}{ll}\text { Bacharelado } & \mathrm{em} \\
\text { Biblioteconomia } & \end{array}$ \\
\hline & & & $\begin{array}{ll}\text { Bacharelado } & \text { em } \\
\text { Biblioteconomia } & \end{array}$ \\
\hline & & Universidade São Paulo - USP & $\begin{array}{lr}\text { Bacharelado } & \text { em } \\
\text { Biblioteconomia e } & \text { Ciência } \\
\text { da Informação } & \text { e } \\
\text { Documentação } & \end{array}$ \\
\hline & & $\begin{array}{l}\text { Universidade Estadual Paulista } \\
\text { "Júlio de Mesquita Filho" - UNESP }\end{array}$ & $\begin{array}{l}\text { Bacharelado } \\
\text { Biblioteconomia }\end{array}$ \\
\hline & & $\begin{array}{l}\text { Universidade Federal de São Carlos } \\
\text { - UFSCar }\end{array}$ & $\begin{array}{l}\text { Bacharelado em } \\
\text { Biblioteconomia e Ciência } \\
\text { da Informação }\end{array}$ \\
\hline & \multirow{2}{*}{ MINAS GERAIS } & $\begin{array}{l}\text { Centro Universitário de Formiga - } \\
\text { UNIFOR }\end{array}$ & $\begin{array}{l}\text { Bacharelado } \\
\text { Biblioteconomia }\end{array}$ \\
\hline & & $\begin{array}{l}\text { Universidade Federal de Minas } \\
\text { Gerais - UFMG }\end{array}$ & $\begin{array}{l}\text { Bacharelado } \\
\text { Biblioteconomia }\end{array}$ \\
\hline & $\begin{array}{l}\text { ESPÍRITO } \\
\text { SANTO }\end{array}$ & $\begin{array}{l}\text { Universidade Federal do Espírito } \\
\text { Santo- UFES }\end{array}$ & $\begin{array}{l}\text { Bacharelado } \\
\text { Biblioteconomia }\end{array}$ \\
\hline SUL & $\begin{array}{l}\text { RIO GRANDE } \\
\text { DO SUL }\end{array}$ & $\begin{array}{l}\text { Fundação Universidade Federal do } \\
\text { Rio Grande - FURG }\end{array}$ & $\begin{array}{l}\text { Bacharelado } \\
\text { Biblioteconomia }\end{array}$ \\
\hline
\end{tabular}




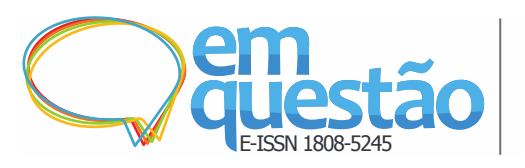

A construção da atual fundamentação do pensamento biblioteconômico-informacional nos cursos de graduação em Biblioteconomia no Brasil Priscila de Souza Figueira Cervo e Gustavo Silva Saldanha

\begin{tabular}{|c|c|c|c|c|}
\hline & & $\begin{array}{l}\text { Universidade Federal do Rio Grande } \\
\text { do Sul - UFRGS }\end{array}$ & $\begin{array}{l}\text { Bacharelado } \\
\text { Biblioteconomia }\end{array}$ & em \\
\hline & \multirow[t]{2}{*}{$\begin{array}{l}\text { SANTA } \\
\text { CATARINA }\end{array}$} & $\begin{array}{l}\text { Universidade do Estado de Santa } \\
\text { Catarina - UDESC }\end{array}$ & $\begin{array}{l}\text { Bacharelado } \\
\text { Biblioteconomia } \\
\text { Habilitação em Gestão } \\
\text { Informação }\end{array}$ & $\begin{array}{r}\text { em } \\
\text { da }\end{array}$ \\
\hline & & $\begin{array}{l}\text { Universidade Federal de Santa } \\
\text { Catarina- UFSC }\end{array}$ & $\begin{array}{l}\text { Bacharelado } \\
\text { Biblioteconomia }\end{array}$ & \\
\hline & \multirow{2}{*}{ PARANÁ } & $\begin{array}{l}\text { Universidade Estadual de Londrina - } \\
\text { UEL }\end{array}$ & $\begin{array}{l}\text { Bacharelado } \\
\text { Biblioteconomia }\end{array}$ & em \\
\hline & & $\begin{array}{l}\text { Universidade Federal do Paraná - } \\
\text { UFPR }\end{array}$ & $\begin{array}{l}\text { Bacharelado em Gestão } \\
\text { Informação }\end{array}$ & da \\
\hline \multirow{4}{*}{$\begin{array}{l}\text { CENTRO- } \\
\text { OESTE }\end{array}$} & $\begin{array}{l}\text { MATO } \\
\text { GROSSO } \\
\text { DO SUL }\end{array}$ & $\begin{array}{l}\text { Instituto de Ensino Superior da } \\
\text { Funlec-IESF }\end{array}$ & $\begin{array}{l}\text { Bacharelado } \\
\text { Biblioteconomia }\end{array}$ & $\mathrm{em}$ \\
\hline & $\begin{array}{l}\text { MATO } \\
\text { GROSSO }\end{array}$ & Centro Universitário UNIRONDON & $\begin{array}{l}\text { Bacharelado } \\
\text { Biblioteconomia }\end{array}$ & $\mathrm{em}$ \\
\hline & GOIÁS & $\begin{array}{l}\text { Universidade Federal de Goiás - } \\
\text { UFG }\end{array}$ & $\begin{array}{l}\text { Bacharelado } \\
\text { Biblioteconomia }\end{array}$ & em \\
\hline & BRASÍLIA & Universidade de Brasília - UnB & $\begin{array}{l}\text { Bacharelado } \\
\text { Biblioteconomia }\end{array}$ & em \\
\hline \multirow{8}{*}{ NORDESTE } & BAHIA & $\begin{array}{l}\text { Universidade Federal da Bahia - } \\
\text { UFBA }\end{array}$ & $\begin{array}{l}\text { Bacharelado } \\
\text { Biblioteconomia } \\
\text { Documentação }\end{array}$ & $\mathrm{em}$ \\
\hline & PARAÍbA & $\begin{array}{l}\text { Universidade Federal da Paraíba - } \\
\text { UFPb }\end{array}$ & $\begin{array}{l}\text { Bacharelado } \\
\text { Biblioteconomia }\end{array}$ & em \\
\hline & ALAGOAS & $\begin{array}{l}\text { Universidade Federal de Alagoas - } \\
\text { UFAL }\end{array}$ & $\begin{array}{l}\text { Bacharelado } \\
\text { Biblioteconomia }\end{array}$ & $\mathrm{em}$ \\
\hline & PERNAMBUCO & $\begin{array}{l}\text { Universidade Federal de } \\
\text { Pernambuco - UFPE }\end{array}$ & $\begin{array}{l}\text { Bacharelado } \\
\text { Biblioteconomia }\end{array}$ & em \\
\hline & MARANHÃO & $\begin{array}{l}\text { Universidade Federal do Maranhão - } \\
\text { UFMA }\end{array}$ & $\begin{array}{l}\text { Bacharelado } \\
\text { Biblioteconomia }\end{array}$ & em \\
\hline & & $\begin{array}{l}\text { Universidade Federal do Ceará - } \\
\text { UFC }\end{array}$ & $\begin{array}{l}\text { Bacharelado } \\
\text { Biblioteconomia }\end{array}$ & em \\
\hline & & $\begin{array}{l}\text { Universidade Federal do Cariri - } \\
\text { UFCA }\end{array}$ & $\begin{array}{l}\text { Bacharelado } \\
\text { Biblioteconomia }\end{array}$ & em \\
\hline & $\begin{array}{l}\text { RIO GRANDE } \\
\text { DO NORTE }\end{array}$ & $\begin{array}{l}\text { Universidade Federal do Rio Grande } \\
\text { do Norte - UFRN }\end{array}$ & $\begin{array}{l}\text { Bacharelado } \\
\text { Biblioteconomia }\end{array}$ & $\mathrm{em}$ \\
\hline \multirow{2}{*}{ NORTE } & PARÁ & $\begin{array}{l}\text { Universidade Federal do Pará - } \\
\text { UFPA }\end{array}$ & $\begin{array}{l}\text { Bacharelado } \\
\text { Biblioteconomia }\end{array}$ & em \\
\hline & AMAZONAS & Universidade Federal do Amazonas - & Bacharelado & em \\
\hline
\end{tabular}

Em Questão, Porto Alegre, v. 24, n. 2, p. 127-164, maio/ago. 2018 


\begin{tabular}{|c|c|l|c|}
\hline & UFAM & Biblioteconomia \\
\hline & TOTAL & 33 & 35 \\
\hline
\end{tabular}

Fonte: ABECIN (2016).

A distinções terminológicas esquematizadas no Quadro 1 demonstram, para além das diferenças, as lutas epistêmicas do campo, sob as teorizações colonizadoras de noções como documentation e informacion science. Identificamos aqui (ressalvados os problemas encontrados e relatados nos procedimentos metodológicos) um total de 35 cursos de graduação em Biblioteconomia no território brasileiro na atualidade. Podemos observar também que esses cursos estão distribuídos entre 33 instituições de ensino superior. O número diferenciado se dá em razão de duas universidades federais do Sudeste possuírem dois cursos da área cada uma. Dessas, a primeira identificada é a Unirio, situada no Estado do Rio de Janeiro, que oferece os cursos de Bacharelado e Licenciatura em Biblioteconomia; no Estado de São Paulo encontramos a USP, que possui o curso de Bacharelado em Biblioteconomia na cidade de São Paulo, e o curso de Bacharelado em Biblioteconomia e Ciência da Informação \& Documentação na cidade de Ribeirão Preto.

Ainda sobre a USP - Ribeirão Preto, podemos acrescentar que o seu curso apresenta variação de nomenclatura nas distintas fontes consultadas. $\mathrm{O}$ nome do curso no portal da ABECIN se encontra na forma acima apresentada; no portal da universidade, com outra formação; quando chegamos à matriz, identificamos outra configuração. Em tais variações, ora a noção “biblioteconomia” é alocada no começo do título, ora no fim, ora inexiste.

Para sintetizar a relação de convergência e de afastamento da padronização terminológica, a Tabela 1 reúne as nomenclaturas coincidentes dos cursos de graduação. 
Tabela 1 - Nomenclatura dos cursos de Biblioteconomia mapeados no território brasileiro

\begin{tabular}{|c|c|c|}
\hline INSTITUIÇÃO & NOME DO CURSO & TOTAL \\
\hline $\begin{array}{l}\text { UNIRIO; FAINC, PUC Campinas; UNIFAI; } \\
\text { USP; UNESP; UNIFOR; UFMG; UFES; } \\
\text { FURG; UFRGS; IESF; UnB; UFSC; UEL; } \\
\text { UFPb; UFAL; UFG; UFPE; UFAM; UFC; } \\
\text { UFCA; UFMA; UFPA; UFRN }\end{array}$ & Bacharelado em Biblioteconomia & 25 \\
\hline UFF; UFBA & $\begin{array}{l}\text { Bacharelado em Biblioteconomia e } \\
\text { Documentação }\end{array}$ & 2 \\
\hline FESPSP; UFSCar & $\begin{array}{l}\text { Bacharelado em Biblioteconomia e Ciência } \\
\text { da Informação }\end{array}$ & 2 \\
\hline USP - Campus Ribeirão Preto & $\begin{array}{l}\text { Bacharelado em Biblioteconomia e Ciência } \\
\text { da Informação e Documentação }\end{array}$ & 1 \\
\hline UFRJ & $\begin{array}{l}\text { Bacharelado em Biblioteconomia e Gestão } \\
\text { de Unidades de Informação }\end{array}$ & 1 \\
\hline UFPR & Bacharelado em Gestão da Informação & 1 \\
\hline UNIRIO & Licenciatura em Biblioteconomia & 1 \\
\hline \multicolumn{2}{|l|}{ TOTAL } & 33 \\
\hline
\end{tabular}

Fonte: Centro Universitário Assunção (2016); Centro Universitário de Formiga (2016); Faculdades Integradas Coração de Jesus (2016); Fundação Escola de Sociologia e Política de São Paulo (2016); Instituto de Ensino Superior da Funlec (2016); Pontifícia Universidade Católica de Campinas (2016); Universidade de Brasília (2016); Universidade de São Paulo (2016); Universidade Estadual de Londrina (2016); Universidade Estadual Paulista (2016); Universidade Federal da Bahia (2016); Universidade Federal da Paraíba (2016); Universidade Federal de Alagoas (2016); Universidade Federal de Goiás (2016); Universidade Federal de Minas Gerais (2016); Universidade Federal de Pernambuco (2016); Universidade Federal de Santa Catarina (2016); Universidade Federal de São Carlos (2016); Universidade de São Paulo (2016); Universidade Federal do Amazonas (2016); Universidade Federal do Ceará (2016); Universidade Federal do Cariri (2016); Universidade Federal do Espírito Santo (2016); Universidade Federal do Estado do Rio de Janeiro (2016); Universidade Federal do Maranhão (2016); Universidade Federal do Pará (2016); Universidade Federal do Paraná (2016); Universidade Federal do Rio de Janeiro (2016); Universidade Federal do Rio Grande (2016); Universidade Federal do Rio Grande do Norte (2016); Universidade Federal do Rio Grande do Sul (2016); Universidade Federal Fluminense (2016).

Como podemos observar, a maioria dos cursos tem por nome apenas o uso do termo "biblioteconomia", mas existem as variações (sob as quais as lutas epistêmicas ganham visibilidade). Encontramos aqueles que integraram outros termos às nomenclaturas de seus cursos, incluindo "documentação", ou "ciência da informação", ou ambos, além da noção de "gestão da informação", repercutindo a mutação história dos anos 1950 em diante, concentrada no Brasil 
nos anos 1990, apontada em nosso referencial teórico no âmbito da luta histórico-epistêmica sob as noções documentation e information science.

No plano das disciplinas de fundamentação do campo, os problemas se multiplicam no cenário epistemológico. Apesar do desenvolvimento da pósgraduação stricto sensu ao longo de quase 50 anos, a preocupação com os aportes de fundamentação revela um problema ainda flagrante. Dos 33 cursos, 25 possuem uma disciplina "formal" de fundamentação e, desses, a variação terminológica aponta para possíveis dificuldades de compreensão da proposta estrutural de configuração epistemológica (a assertiva, no entanto, não diz respeito aqui à negação da relevância e mesmo da urgência da pluralidade das teorias do conhecimento no campo, mas atenta-se para o vazio epistemológico potencializado na abertura de significantes e significados sem abordagem crítico-reflexiva). Na Tabela 2 estão dispostos os 25 cursos e o nome das respectivas disciplinas identificadas.

Tabela 2 - Nomenclatura das disciplinas de fundamentação do campo biblioteconômicoinformacional no território brasileiro

\begin{tabular}{l|l|l}
\multicolumn{1}{c|}{ INSTITUIÇÃO } & \multicolumn{1}{c}{ NOME DA DISCIPLINA } & TOTAL \\
\hline $\begin{array}{l}\text { UNIRIO - Bacharelado; } \\
\text { UNIRIO - Licenciatura; } \\
\begin{array}{l}\text { UFES; UFPB; UFPE; } \\
\text { UFSC; UFMA }\end{array}\end{array}$ & Fundamentos da/de Biblioteconomia & 7 \\
\hline $\begin{array}{l}\text { UFF; UNESP; UFAM; } \\
\text { UFC; UFCA }\end{array}$ & Introdução à Biblioteconomia & 5 \\
\hline $\begin{array}{l}\text { UFRJ; FESPSP; FURG; } \\
\text { UFRN }\end{array}$ & $\begin{array}{l}\text { Fundamentos da/em Biblioteconomia e Ciência da } \\
\text { Informação }\end{array}$ & 4 \\
\hline USP; UFSCar; UFG & $\begin{array}{l}\text { Fundamentos em Biblioteconomia, Documentação e Ciência } \\
\text { da Informação }\end{array}$ & 3 \\
\hline PUC - Campinas & Fundamentos da Ciência da Informação e Biblioteconomia & 1 \\
\hline UFMG & Introdução à Biblioteconomia, Arquivologia e Museologia & 1 \\
\hline UnB; UDESC; UFBA; & Introdução à Biblioteconomia e Ciência da Informação & 4 \\
\hline UFAL & & $\mathbf{2 5}$ \\
\hline TOTAL &
\end{tabular}

Fonte: Fundação Escola de Sociologia e Política de São Paulo (2016); Pontifícia Universidade Católica de Campinas (2016); Universidade de Brasília (2016); Universidade de São Paulo 
(2016); Universidade Estadual Paulista (2016); Universidade Federal da Bahia (2016); Universidade Federal da Paraíba (2016); Universidade Federal de Alagoas (2016); Universidade Federal de Goiás (2016); Universidade Federal de Minas gerais (2016); Universidade Federal de Pernambuco (2016); Universidade Federal de Santa Catarina (2016); Universidade Federal de São Carlos (2016); Universidade de São Paulo (2016); Universidade Federal do Amazonas (2016); Universidade Federal do Ceará (2016); Universidade Federal do Cariri (2016); Universidade Federal do Espírito Santo (2016); Universidade Federal do Estado do Rio de Janeiro (2016); Universidade Federal do Maranhão (2016); Universidade Federal do Rio de Janeiro (2016); Universidade Federal do Rio Grande (2016); Universidade Federal do Rio Grande do Norte (2016).

As instituições FAINC, UNIFAI, USP - Campus Ribeirão Preto, UNIFOR, UEL, UFRGS, UFPR e UFPA, não possuem disciplina formal de fundamentação. No caso das instituições UNIFOR e UFPA, não foi possível encontrar alguma disciplina como alternativa de análise da ementa, portanto dessa etapa em diante elas ficarão de fora das comparações. Já para as outras seis instituições identificamos as disciplinas sobre nomenclaturas com variação terminológica, a saber, UNIFAI (Introdução à Ciência da Informação), FAINC (Ciência da Informação e Biblioteconomia), USP - Campus Ribeirão Preto (Ciência da Informação), UEL (Introdução à Ciência da Informação), UFRGS (Introdução às Ciências da Informação, e Fundamentos da Ciência da Informação A) e UFPR (Fundamentos de Ciência da Informação), mas infelizmente nem todas tiveram as ementas identificadas no momento de coleta de dados.

Registra-se, pois, a ausência de dadas instituições em algumas etapas da análise a seguir (ou seja, formações universitárias no campo identificadas a partir da caraterística das nomenclaturas, mas sobre as quais não foi possível aprofundar a reflexão sobre as ementas e os planos de estudo). Faz-se necessário observar e enfatizar a ressalva, atestando que, em diferentes casos, ocorreu, igualmente, a impossibilidade de aquisição dos dados para o corpus verticalizado, por razões técnicas de acesso às fontes eletrônicas, no período da coleta, o que formaliza a ausência de uma ou outra instituição na apresentação das análises refinadas.

Sobre os cursos incluídos no corpus com presença de mais de uma disciplina, obtivemos: UNIRIO - Bacharelado e Licenciatura, com três disciplinas Introdução à Biblioteconomia, Fundamentos da Bibliografia e 
Documentação, e Introdução à Ciência da Informação; UNESP (Introdução à Biblioteconomia, e Introdução à Ciência da Informação); UFMG (Introdução à Biblioteconomia, Arquivologia e Museologia, e Fundamentos da Ciência da Informação) e UFPE (Fundamentos de Biblioteconomia, e Biblioteconomia e Pensamento Científico).

$\mathrm{Na}$ análise das ementas das disciplinas selecionadas obtivemos um panorama dos conceitos centrais da fundamentação do ensino de Biblioteconomia nesses cursos. A Tabela 3 relaciona as disciplinas que, no contexto de produção do corpus, permitiram a análise das ementas.

Tabela 3 - Disciplinas das quais foram extraídos os conceitos centrais das ementas

\begin{tabular}{|c|c|c|}
\hline NOME DA DISCIPLINA & INSTITUIÇÃO & TOTAL \\
\hline Introdução à Biblioteconomia & UFF; UNESP; UFSC; UFC; UFCA & 5 \\
\hline $\begin{array}{l}\text { Introdução à Biblioteconomia e } \\
\text { Ciência da Informação }\end{array}$ & UDESC; UnB; UFBA & 4 \\
\hline $\begin{array}{l}\text { Fundamentos } \\
\text { Biblioteconomia e Ciência da da } \\
\text { Informação }\end{array}$ & UFRJ; FESPSP; FURG; UFRN & 4 \\
\hline $\begin{array}{ll}\text { Fundamentos } & \mathrm{da} / \mathrm{de} \\
\text { Biblioteconomia } & \end{array}$ & $\begin{array}{l}\text { UNIRIO - Bacharelado e Licenciatura; } \\
\text { UFES; UFPE }\end{array}$ & 3 \\
\hline $\begin{array}{l}\text { Fundamentos em Biblioteconomia, } \\
\text { Documentação e Ciência da } \\
\text { Informação }\end{array}$ & USP; UFSCar; UFG & 3 \\
\hline $\begin{array}{l}\text { Introdução à/às Ciência/Ciências da } \\
\text { Informação }\end{array}$ & $\begin{array}{l}\text { UNIRIO - Bacharelado e Licenciatura; } \\
\text { UEL; UNESP; UNIFAI; UFRGS }\end{array}$ & 3 \\
\hline $\begin{array}{l}\text { Fundamentos de/da Ciência da } \\
\text { Informação }\end{array}$ & UFPR; UFMG; UFRGS & 2 \\
\hline $\begin{array}{l}\text { Biblioteconomia e Pensamento } \\
\text { Científico }\end{array}$ & UFPE & 1 \\
\hline $\begin{array}{l}\text { Fundamentos da Bibliografia e } \\
\text { Documentação }\end{array}$ & UNIRIO - Bacharelado e Licenciatura & 1 \\
\hline $\begin{array}{l}\text { Fundamentos da Ciência da } \\
\text { Informação e Biblioteconomia }\end{array}$ & PUC - Campinas & 1 \\
\hline $\begin{array}{l}\text { Introdução à Biblioteconomia, } \\
\text { Arquivologia e Museologia }\end{array}$ & UFMG & 1 \\
\hline $\begin{array}{l}\text { Ciência da Informação e } \\
\text { Biblioteconomia }\end{array}$ & FAINC & 1 \\
\hline
\end{tabular}




\begin{tabular}{l|l|c}
\hline Ciência da Informação & USP - Campus Ribeirão Preto & 1 \\
\hline TOTAL & & $\mathbf{3 0}$ \\
\hline
\end{tabular}

Fonte: Centro Universitário Assunção (2016); Centro Universitário de Formiga (2016); Faculdades Integradas Coração de Jesus (2016); Fundação Escola de Sociologia e Política de São Paulo (2016); Instituto de Ensino Superior da Funlec (2016); Pontifícia Universidade Católica de Campinas (2016); Universidade de Brasília (2016); Universidade de São Paulo (2016); Universidade Estadual de Londrina (2016); Universidade Estadual Paulista (2016); Universidade Federal da Bahia (2016); Universidade Federal da Paraíba (2016); Universidade Federal de Alagoas (2016); Universidade Federal de Goiás (2016); Universidade Federal de Minas Gerais (2016); Universidade Federal de Pernambuco (2016); Universidade Federal de Santa Catarina (2016); Universidade Federal de São Carlos (2016); Universidade de São Paulo (2016); Universidade Federal do Amazonas (2016); Universidade Federal do Ceará (2016); Universidade Federal do Cariri (2016); Universidade Federal do Espírito Santo (2016); Universidade Federal do Estado do Rio de Janeiro (2016); Universidade Federal do Maranhão (2016); Universidade Federal do Pará (2016); Universidade Federal do Paraná (2016); Universidade Federal do Rio de Janeiro (2016); Universidade Federal do Rio Grande (2016); Universidade Federal do Rio Grande do Norte (2016); Universidade Federal do Rio Grande do Sul (2016); Universidade Federal Fluminense (2016).

A partir dos dados apresentados pela Tabela 3, atingimos o território conceitual de fundamentação do campo no contexto da graduação. A seleção de conceitos foi feita a partir da identificação e do estudo das ementas, levando em consideração as categorias analíticas do referencial teórico, ou seja, as marcas nocionais possibilitadas pela literatura de formação histórico-teórica do campo, principalmente sob a abordagem de Shera \& Cleveland (1977).

Quadro 2 - Conceitos das ementas de fundamentação biblioteconômico-informacional por região e instituição

\begin{tabular}{|c|c|c|}
\hline REGIÃO & INSTITUIÇÃO & CONCEITOS \\
\hline \multirow{4}{*}{ SUDESTE } & UFF & $\begin{array}{l}\text { Biblioteconomia; Sistema de informação; Recuperação da informação; } \\
\text { Profissional da informação; Biblioteca. }\end{array}$ \\
\hline & UFRJ & $\begin{array}{l}\text { Biblioteconomia; Ciência da informação; Técnicas documentárias; } \\
\text { Processo de comunicação; Mercado de trabalho. }\end{array}$ \\
\hline & $\begin{array}{l}\text { UNIRIO - } \\
\text { Bacharelado e } \\
\text { Licenciatura }\end{array}$ & $\begin{array}{l}\text { 1) IB: Biblioteconomia; Pensamento biblioteconômico; História; } \\
\text { Instituições biblioteconômicas. } \\
\text { 2) FBD: Bibliografia; Controle Bibliográfico; Serviços Bibliográficos; } \\
\text { Documentação. } \\
\text { 3) IC: Ciência da Informação; Teoria Geral dos Sistemas; Teoria da } \\
\text { Comunicação; Centros de Informação e Cultura; Sociedade de } \\
\text { Informação; Processos de Automação. }\end{array}$ \\
\hline & FAINC & $\begin{array}{l}\text { Fundamentos; Biblioteconomia; Documentação; Ciência da } \\
\text { informação; Terminologias; Unidades de informação; Mercado de } \\
\text { trabalho; Profissional da informação; Legislação. }\end{array}$ \\
\hline
\end{tabular}




\begin{tabular}{|c|c|c|}
\hline & FESPSP & $\begin{array}{l}\text { Mercado de trabalho; Biblioteconomia; Documentação; Ciência da } \\
\text { informação; Bibliotecário. }\end{array}$ \\
\hline & PUC Campinas & Fundamentos; Ciência da informação; Biblioteconomia. \\
\hline & USP & $\begin{array}{l}\text { Fundamentos; Paradigmas; Biblioteconomia; Documentação; } \\
\text { Museologia; Arquivologia; Ciência da informação; Territórios de } \\
\text { atuação. }\end{array}$ \\
\hline & $\begin{array}{l}\text { USP Ribeirão } \\
\text { Preto }\end{array}$ & $\begin{array}{l}\text { Bibliografia; Documentação; Biblioteconomia; Arquivística; } \\
\text { Museologia; Ciência da informação. }\end{array}$ \\
\hline & UNESP & $\begin{array}{l}\text { 1) IB: Biblioteconomia; Atuação profissional. } \\
\text { 2) ICI: Ciência da Informação; Arquivologia; Biblioteconomia; } \\
\text { Arquivistas; Bibliotecários. }\end{array}$ \\
\hline & UFSCAR & $\begin{array}{l}\text { Biblioteconomia; Documentação; Ciência da informação; Função } \\
\text { documentária; Unidades de informação; Legislação; Bibliotecários. }\end{array}$ \\
\hline & UFMG & $\begin{array}{l}\text { 1) IBAM: Biblioteconomia; Ciência da informação; Documentos } \\
\text { científicos; Instituições de informação; Sistemas de informação; } \\
\text { Profissional da informação; Bibliotecas; Bibliotecário. } \\
\text { 2) FCI: Ciência da informação; Ciências sociais aplicadas; Paradigmas. }\end{array}$ \\
\hline & UFES & $\begin{array}{l}\text { Biblioteconomia; Informação; Ciclo da comunicação; Unidades de } \\
\text { informação; Socialização do conhecimento; Atividade profissional; } \\
\text { Bibliotecário. }\end{array}$ \\
\hline \multirow{5}{*}{ SUL } & UFRGS & $\begin{array}{l}\text { Arquivologia; Biblioteconomia; Museologia. Documentos; } \\
\text { Profissionais da informação; Formação; Legislação; Atuação; } \\
\text { Entidades (ligadas à Ciência da Informação). }\end{array}$ \\
\hline & FURG & $\begin{array}{l}\text { Fundamentos; Biblioteconomia; Ciência da informação; Terminologia; } \\
\text { Ensino; Suportes da informação; Unidades de informação; Aspectos } \\
\text { legais. }\end{array}$ \\
\hline & UDESC & $\begin{array}{l}\text { Biblioteconomia; Documentação; Ciência da informação; Unidades de } \\
\text { informação; Legislação profissional; Movimento associativo. }\end{array}$ \\
\hline & UFSC & Profissionais da informação. \\
\hline & UEL & $\begin{array}{l}\text { Ciência da informação; Arquivologia; Biblioteconomia; Ciência da } \\
\text { informação. }\end{array}$ \\
\hline \multirow{3}{*}{$\begin{array}{l}\text { CENTRO- } \\
\text { OESTE }\end{array}$} & UFPR & Ciência da informação; Processos de comunicação. \\
\hline & UFG & $\begin{array}{l}\text { Fundamentos; Biblioteconomia; Documentação; Ciência da } \\
\text { informação; Arquivologia; Museologia; Unidades de informação; } \\
\text { Mercado de trabalho; Profissional da informação; Legislação. }\end{array}$ \\
\hline & UNB & $\begin{array}{l}\text { Biblioteconomia; Ciência da informação; Biblioteca; Conservação; } \\
\text { Unidades de informações; Transferência da informação; Bibliotecário; } \\
\text { Pesquisa. }\end{array}$ \\
\hline \multirow[b]{2}{*}{ NORDESTE } & UFBA & $\begin{array}{l}\text { Biblioteconomia; Documentação; Ciência da informação; Biblioteca; } \\
\text { Profissional bibliotecário; Mercado de trabalho; Formação; Legislação. }\end{array}$ \\
\hline & UFPE & $\begin{array}{l}\text { 1) FB: Biblioteconomia; Comunicação; Informação; Profissional } \\
\text { bibliotecário. } \\
\text { 2) BPI: Pensamento científico; Conhecimento ocidental; } \\
\text { Biblioteconomia; Informação e conhecimento. }\end{array}$ \\
\hline
\end{tabular}




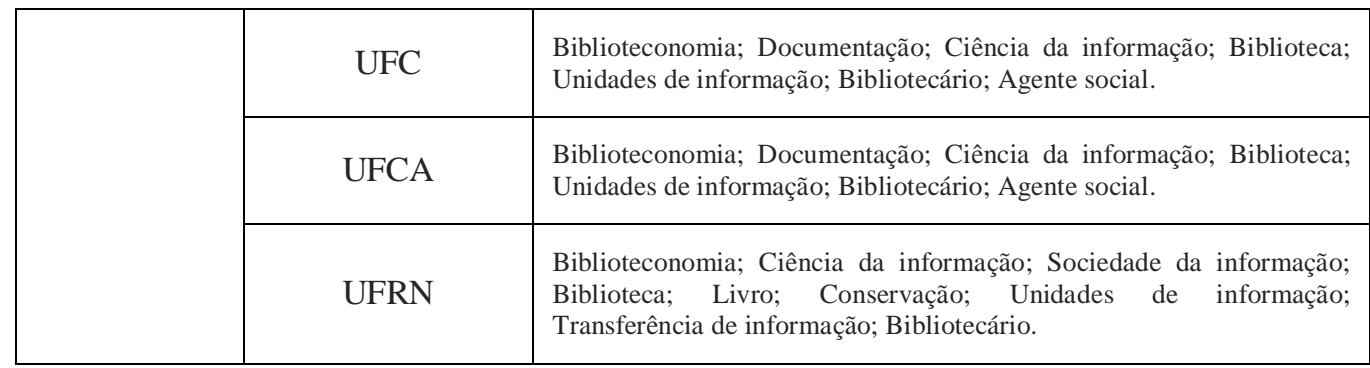

fonte: centro universitário assunção (2016); centro universitário de formiga (2016); faculdades integradas coração de jesus (2016); fundação escola de sociologia e política de são paulo (2016); instituto de ensino superior da funlec (2016); pontifícia universidade católica de campinas (2016); universidade de brasília (2016); universidade de são paulo (2016); universidade estadual de londrina (2016); universidade estadual paulista (2016); universidade federal da bahia (2016); universidade federal da paraíba (2016); universidade federal de alagoas (2016); universidade federal de goiás (2016); universidade federal de minas gerais (2016); universidade federal de pernambuco (2016); universidade federal de santa catarina (2016); universidade federal de são carlos (2016); universidade de são paulo (2016); universidade federal do amazonas (2016); universidade federal do ceará (2016); universidade federal do cariri (2016); universidade federal do espírito santo (2016); universidade federal do estado do rio de janeiro (2016); universidade federal do maranhão (2016); universidade federal do pará (2016); universidade federal do paraná (2016); universidade federal do rio de janeiro (2016); universidade federal do rio grande (2016); universidade federal do rio grande do norte (2016); universidade federal do rio grande do sul (2016); universidade federal fluminense (2016).

A partir do quadro acima podemos cruzar os dados da Tabela 3 e discutir as possíveis problemáticas da relação entre fundamentação, terminologia e estrutura conceitual de fundamentação. Para o passo da extração conceitual, optamos por reconhecer, a partir da subjetividade do referencial teórico, o "conceito principal" da ementa, movimento metodológico estabelecido sob o critério da ênfase inicial e final da proposta de mapeamento, visualizada na Tabela 4.

Tabela 4 - Quantitativo de conceitos das ementas de fundamentação biblioteconômicoinformacional por instituição e por ocorrência

\begin{tabular}{l|l|c}
\hline \multicolumn{1}{c|}{ CONCEITO } & \multicolumn{1}{c|}{ INSTITUIÇÃO } & TOTAL \\
\hline \multirow{5}{*}{ Biblioteconomia } & $\begin{array}{l}\text { UFF; UFRJ; UNIRIO - Bacharelado e Licenciatura; FAINC; } \\
\text { FESPSP; PUC - Campinas; USP; USP - Ribeirão Preto; } \\
\text { UNESP; UFSCAR; UFMG; UFES; UFRGS; FURG; UDESC; } \\
\text { UEL; UFG; UnB; UFBA; UFPE; UFC; UFCA; UFRN; }\end{array}$ & 22 \\
\hline \multirow{5}{*}{ Ciência da informação } & $\begin{array}{l}\text { UFRJ; FAINC; FESPSP; PUC - Campinas; USP; USP - } \\
\text { Ribeirão Preto; UNESP; UFSCAR; UFMG; FURG; UDESC; } \\
\text { UEL; UFPR; UFG; UnB; UFBA; UFC; UFCA; UFRN; } \\
\text { UNIRIO - Bacharelado e Licenciatura; }\end{array}$ & 19 \\
\hline \multirow{2}{*}{ Documentação } & $\begin{array}{l}\text { FAINC; FESPSP; USP; USP - Ribeirão Preto; UFSCAR; } \\
\text { UDESC; UFG; UFBA; UFC; UFCA; UNIRIO - Bacharelado e }\end{array}$ & 10 \\
\hline \hline
\end{tabular}

Em Questão, Porto Alegre, v. 24, n. 2, p. 127-164, maio/ago. 2018 


\begin{tabular}{|c|c|c|}
\hline & Licenciatura; & \\
\hline $\begin{array}{l}\text { Unidades } \\
\text { informação(ões) }\end{array}$ & $\begin{array}{l}\text { FAINC; UFSCAR; UFES; FURG; UDESC; UFG; UnB; UFC; } \\
\text { UFCA; UFRN; }\end{array}$ & 10 \\
\hline Bibliotecário(s) & $\begin{array}{l}\text { FESPSP; UNESP; UFSCAR; UFMG; UFES; UNB; UFC; } \\
\text { UFCA; UFRN; }\end{array}$ & 9 \\
\hline Biblioteca(s) & UFF; UFMG; UnB; UFBA; UFC; UFCA; UFRN; & 7 \\
\hline $\begin{array}{l}\text { Fundamentos } \quad \text { [sem } \\
\text { conexão com quaisquer } \\
\text { adjetivações] }\end{array}$ & FAINC; PUC - Campinas; USP; FURG; UFG; & 5 \\
\hline Mercado de trabalho & UFRJ; FAINC; FESPSP; UFG; UFBA; & 5 \\
\hline $\begin{array}{l}\text { Profissional(ais) da } \\
\text { informação }\end{array}$ & UFF; FAINC; UFMG; UFRGS; UFSC; UFG; & 5 \\
\hline $\begin{array}{l}\text { Legislação/Aspectos } \\
\text { legais }\end{array}$ & FAINC; UFSCAR; UFRGS; FURG; UFG; UFBA; & 5 \\
\hline Arquivologia & USP; UNESP; UEL; UFG; UFRGS. & 4 \\
\hline Museologia & USP; USP - Ribeirão Preto; UFG; UFRGS. & 3 \\
\hline Agente social & UFC; UFCA; & 2 \\
\hline $\begin{array}{l}\text { Atuação/Atividade } \\
\text { profissional }\end{array}$ & UNESP; UFES; & 2 \\
\hline Conservação & UnB; UFRN; & 2 \\
\hline Paradigmas & USP; UFMG; & 2 \\
\hline Pesquisa & UnB; UFRN; & 2 \\
\hline $\begin{array}{l}\text { Processo(s) de } \\
\text { comunicação }\end{array}$ & UFRJ; UFPR; & 2 \\
\hline $\begin{array}{l}\text { Profissional } \\
\text { bibliotecário }\end{array}$ & UFBA; UFPE; & 2 \\
\hline $\begin{array}{l}\text { Sistema(s) de } \\
\text { informação }\end{array}$ & UFF; UFMG; & 2 \\
\hline Terminologia(s) & FAINC; FURG; & 2 \\
\hline $\begin{array}{l}\text { Transferência da/de } \\
\text { informação }\end{array}$ & UNB; UFRN; & 2 \\
\hline Arquivistas & UNESP; & 1 \\
\hline Arquivística & USP - Ribeirão Preto; & 1 \\
\hline Bibliografia & USP - Ribeirão Preto; UNIRIO - Bacharelado e Licenciatura; & 1 \\
\hline $\begin{array}{l}\text { Centros de informação e } \\
\text { cultura }\end{array}$ & UNIRIO - Bacharelado e Licenciatura; & 1 \\
\hline
\end{tabular}




\begin{tabular}{|c|c|c|}
\hline Ciclo da comunicação & UFES; & 1 \\
\hline $\begin{array}{l}\text { Ciências } \\
\text { aplicadas }\end{array}$ & UFMG; & 1 \\
\hline Comunicação & UFPE; & 1 \\
\hline Conhecimento ocidental & UFPE; & 1 \\
\hline Controle bibliográfico & UNIRIO - Bacharelado e Licenciatura; & 1 \\
\hline $\begin{array}{l}\text { Diálogos } \\
\text { interdisciplinares }\end{array}$ & UNESP; & 1 \\
\hline Documentos científicos & UFMG; & 1 \\
\hline Ensino & FURG; & 1 \\
\hline Formação & UFBA; UFRGS. & 1 \\
\hline Função documentária & UFSCAR; & 1 \\
\hline História & UNIRIO - Bacharelado e Licenciatura; & 1 \\
\hline Informação & UFES; & 1 \\
\hline $\begin{array}{l}\text { Informação } \\
\text { conhecimento }\end{array}$ & UFPE; & 1 \\
\hline $\begin{array}{l}\text { Instituições } \\
\text { biblioteconômicas } \\
\text { Entidades }\end{array}$ & UNIRIO - Bacharelado e Licenciatura; UFRGS. & 1 \\
\hline $\begin{array}{l}\text { Instituições } \\
\text { informação }\end{array}$ & UFMG; & 1 \\
\hline Legislação profissional & UDESC; & 1 \\
\hline Livro & UFRN; & 1 \\
\hline Movimento associativo & UDESC; & 1 \\
\hline $\begin{array}{l}\text { Pensamento } \\
\text { biblioteconômico }\end{array}$ & UNIRIO - Bacharelado e Licenciatura; & 1 \\
\hline Pensamento científico & UFPE; & 1 \\
\hline Processo de automação & UNIRIO - Bacharelado e Licenciatura; & 1 \\
\hline $\begin{array}{l}\text { Recuperação } \quad \text { da } \\
\text { informação }\end{array}$ & UFF; & 1 \\
\hline Serviços bibliográficos & UNIRIO - Bacharelado e Licenciatura; & 1 \\
\hline $\begin{array}{l}\text { Socialização do } \\
\text { conhecimento }\end{array}$ & UFES; & 1 \\
\hline Sociedade $\quad \mathrm{da} / \mathrm{de}$ & UFRN; UNIRIO - Bacharelado e Licenciatura; & 1 \\
\hline
\end{tabular}




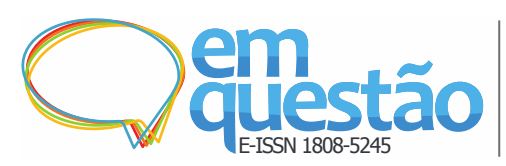

A construção da atual fundamentação do pensamento biblioteconômico-informacional nos cursos de graduação em Biblioteconomia no Brasil Priscila de Souza Figueira Cervo e Gustavo Silva Saldanha

\begin{tabular}{|c|c|c|}
\hline informação & & \\
\hline Suportes da informação & FURG; & 1 \\
\hline Técnicas documentárias & UFRJ; & 1 \\
\hline Teoria da comunicação & UNIRIO - Bacharelado e Licenciatura; & 1 \\
\hline $\begin{array}{l}\begin{array}{l}\text { Teoria } \\
\text { sistemas }\end{array} \\
\text { geral }\end{array}$ & UNIRIO - Bacharelado e Licenciatura; & 1 \\
\hline \begin{tabular}{l} 
Territórios de atuação \} $\\
{\text { Atuação }}$ & USP; UFRGS & 1 \\
\hline
\end{tabular}
\end{tabular}

Fonte: centro universitário assunção (2016); centro universitário de formiga (2016); faculdades integradas coração de jesus (2016); fundação escola de sociologia e política de são paulo (2016); instituto de ensino superior da funlec (2016); pontifícia universidade católica de campinas (2016); universidade de brasília (2016); universidade de são paulo (2016); universidade estadual de londrina (2016); universidade estadual paulista (2016); universidade federal da bahia (2016); universidade federal da paraíba (2016); universidade federal de alagoas (2016); universidade federal de goiás (2016); universidade federal de minas gerais (2016); universidade federal de pernambuco (2016); universidade federal de santa catarina (2016); universidade federal de são carlos (2016); universidade de são paulo (2016); universidade federal do amazonas (2016); universidade federal do ceará (2016); universidade federal do cariri (2016); universidade federal do espírito santo (2016); universidade federal do estado do rio de janeiro (2016); universidade federal do maranhão (2016); universidade federal do pará (2016); universidade federal do paraná (2016); universidade federal do rio de janeiro (2016); universidade federal do rio grande (2016); universidade federal do rio grande do norte (2016); universidade federal do rio grande do sul (2016); universidade federal fluminense (2016).

Ao todo foram mapeados 51 conceitos extraídos das ementas dos cursos de graduação selecionados. Podemos observar que os termos mais presentes são "biblioteconomia" (22 ocorrências), seguido de "ciência da Informação" (19 ocorrências). A partir deste passo, os termos mais comuns identificados foram: “documentação" (10 ocorrências), "bibliotecário(s)" (9 ocorrências), e "Biblioteca(s)" (7 ocorrências).

Outra questão que podemos destacar para observação e análise é a quantidade de disciplinas de fundamentação do curso em relação à quantidade total de disciplinas de sua matriz curricular. Na Tabela 5 colocamos em ênfase tal proporção.

Tabela 5 - Relação proporcional bruta de disciplinas de fundamentação biblioteconômicoinformacional por totalidade de disciplinas de cada curso de graduação

\begin{tabular}{c|c|c}
\hline INSTITUIÇÃO & DISCIPLINAS DE FUNDAMENTAÇÃO & $\begin{array}{c}\text { DISCIPLINAS DE } \\
\text { FUNDAMENTAÇÃO / } \\
\text { TOTAL DE }\end{array}$ \\
\hline
\end{tabular}

Em Questão, Porto Alegre, v. 24, n. 2, p. 127-164, maio/ago. 2018

doi: http://dx.doi.org/10.19132/1808-5245242.127-164 


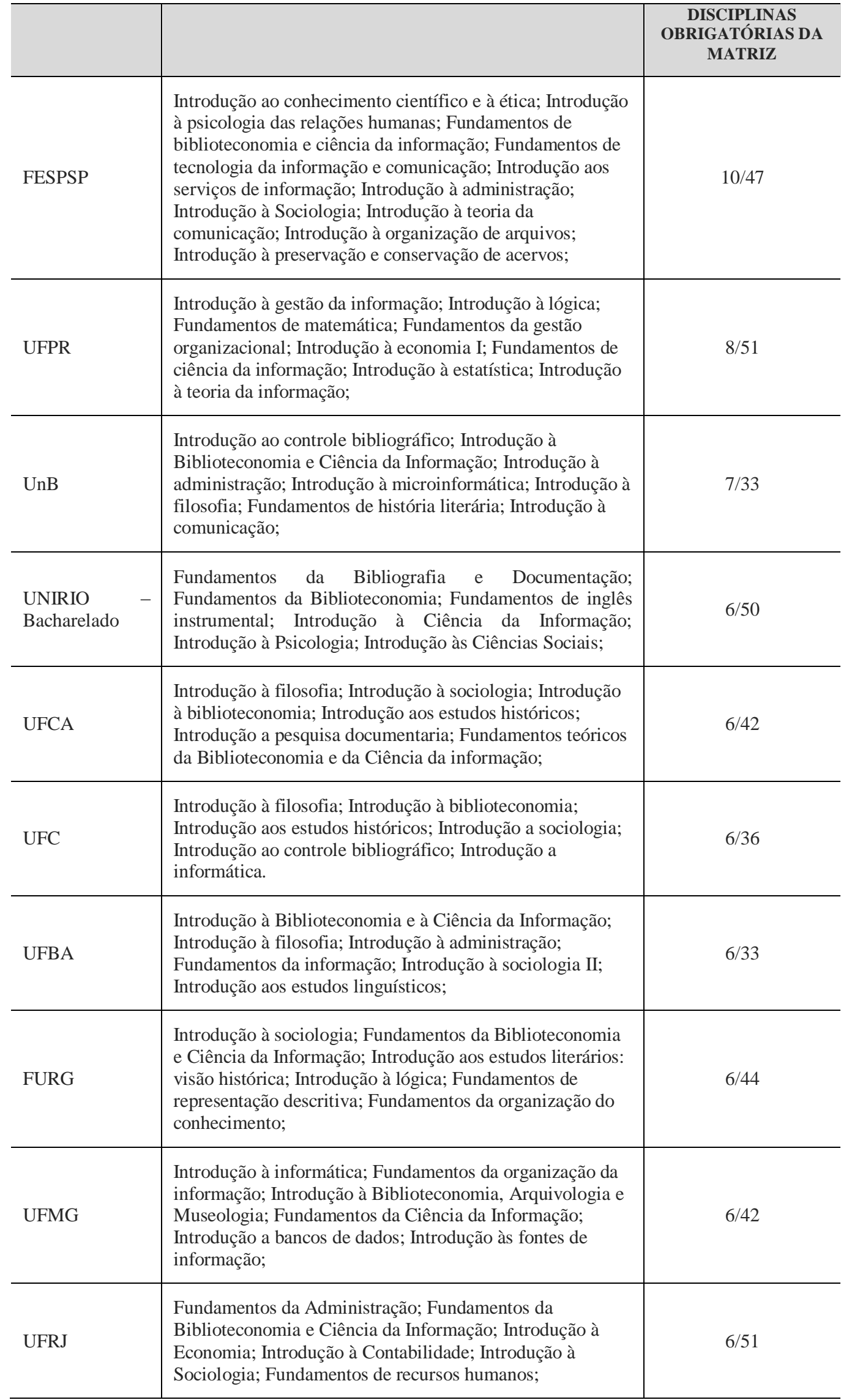




\begin{tabular}{|c|c|c|}
\hline $\begin{array}{l}\text { UNIRIO } \\
\text { Licenciatura }\end{array}$ & $\begin{array}{l}\text { Introdução às Ciências Sociais; Introdução à Psicologia; } \\
\text { Fundamentos da Bibliografia e Documentação; } \\
\text { Fundamentos da Biblioteconomia; Introdução à Ciência da } \\
\text { Informação; }\end{array}$ & $5 / 45$ \\
\hline $\begin{array}{l}\text { USP - Campus } \\
\text { Ribeirão Preto }\end{array}$ & $\begin{array}{l}\text { Introdução à estatística; Introdução às tecnologias de } \\
\text { informação e comunicação; Introdução aos estudos } \\
\text { linguísticos; Introdução à administração; }\end{array}$ & $4 / 35$ \\
\hline UFRGS & $\begin{array}{l}\text { Introdução à sociologia A; Introdução às ciências da } \\
\text { informação; Fundamentos de organização da informação; } \\
\text { Fundamentos da Ciência da Informação A; }\end{array}$ & $4 / 34$ \\
\hline UFSCar & $\begin{array}{l}\text { Introdução à informática; Fundamentos de } \\
\text { Biblioteconomia, Documentação e Ciência da Informação; } \\
\text { Introdução à pesquisa científica; Introdução à análise de } \\
\text { sistemas; }\end{array}$ & $4 / 44$ \\
\hline USP & $\begin{array}{l}\text { Fundamentos em biblioteconomia, documentação e ciência } \\
\text { da informação; Introdução à análise documentária; } \\
\text { Introdução à administração de serviços de informação; } \\
\text { Introdução à pesquisa em ciência da informação; }\end{array}$ & $4 / 33$ \\
\hline UNIFAI & $\begin{array}{l}\text { Introdução à arquivística; Introdução à ciência da } \\
\text { informação; Introdução à lógica; }\end{array}$ & $3 / 39$ \\
\hline UFRN & $\begin{array}{l}\text { Fundamentos em biblioteconomia e ciência da informação; } \\
\text { Introdução à informática; Introdução ao tratamento } \\
\text { temático da informação; }\end{array}$ & $3 / 41$ \\
\hline UFAM & $\begin{array}{l}\text { Introdução à biblioteconomia; Introdução à filosofia; } \\
\text { Introdução à comunicação; }\end{array}$ & $3 / 38$ \\
\hline UFG & $\begin{array}{l}\text { Fundamentos da educação; Fundamentos em } \\
\text { biblioteconomia, documentação e ciência da informação; } \\
\text { Introdução aos estudos literários; }\end{array}$ & $3 / 44$ \\
\hline UFPB & $\begin{array}{l}\text { Fundamentos da ciência da informação; Fundamentos da } \\
\text { biblioteconomia; Fundamentos científicos da comunicação; }\end{array}$ & $3 / 38$ \\
\hline UDESC & $\begin{array}{l}\text { Introdução à Biblioteconomia e Ciência da Informação; } \\
\text { Introdução ao tratamento temático da informação; } \\
\text { Fundamentos da educação; }\end{array}$ & $3 / 45$ \\
\hline UNESP & $\begin{array}{l}\text { Introdução à Ciência da Informação; Introdução à Ciência } \\
\text { da Computação; Introdução à Biblioteconomia; }\end{array}$ & $3 / 43$ \\
\hline UFF & $\begin{array}{l}\text { Fundamentos teóricos em informação I; Fundamentos } \\
\text { teóricos em informação II; Introdução à Biblioteconomia; }\end{array}$ & $3 / 39$ \\
\hline UEL & $\begin{array}{l}\text { Introdução à Ciência da Informação; Introdução à } \\
\text { catalogação; }\end{array}$ & $2 / 49$ \\
\hline UFMA & $\begin{array}{l}\text { Fundamentos de biblioteconomia; Fundamentos de } \\
\text { linguística; }\end{array}$ & $2 / 45$ \\
\hline UFSC & $\begin{array}{l}\text { Fundamentos de Biblioteconomia; Introdução à sociologia } \\
\text { para Biblioteconomia; }\end{array}$ & $2 / 36$ \\
\hline
\end{tabular}




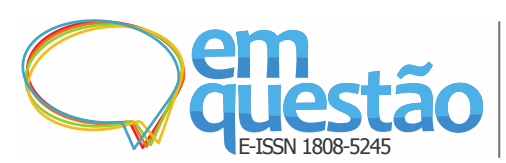

A construção da atual fundamentação do pensamento biblioteconômico-informacional nos cursos de graduação em Biblioteconomia no Brasil

Priscila de Souza Figueira Cervo e Gustavo Silva Saldanha

\begin{tabular}{l|l|c}
\hline UFPE & $\begin{array}{l}\text { Fundamentos de biblioteconomia; Fundamentos de } \\
\text { organização da informação; }\end{array}$ & $2 / 32$ \\
\hline UFAL & $\begin{array}{l}\text { Introdução à informática; Introdução à biblioteconomia e à } \\
\text { ciência da informação; }\end{array}$ & $2 / 38$ \\
\hline UFES & Fundamentos de biblioteconomia; Introdução à filosofia; & $2 / 36$ \\
\hline PUC Campinas & $\begin{array}{l}\text { Fundamentos da Ciência da Informação e Biblioteconomia; } \\
\text { Fundamentos educacionais do profissional bibliotecário; }\end{array}$ & $2 / 61$ \\
\hline UFPA & Fundamentos da filosofia e da lógica; & $1 / 35$ \\
\hline FAINC & Não possui; & $0 / 40$ \\
\hline UNIFOR & Não possui; & $0 / 46$ \\
\hline
\end{tabular}

Fonte: Centro Universitário Assunção (2016); Centro Universitário de Formiga (2016); Faculdades Integradas Coração de Jesus (2016); Fundação Escola de Sociologia e Política de São Paulo (2016); Instituto de Ensino Superior da Funlec (2016); Pontifícia Universidade Católica de Campinas (2016); Universidade de Brasília (2016); Universidade de São Paulo (2016); Universidade Estadual de Londrina (2016); Universidade Estadual Paulista (2016); Universidade Federal da Bahia (2016); Universidade Federal da Paraíba (2016); Universidade Federal de Alagoas (2016); Universidade Federal de Goiás (2016); Universidade Federal de Minas Gerais (2016); Universidade Federal de Pernambuco (2016); Universidade Federal de Santa Catarina (2016); Universidade Federal de São Carlos (2016); Universidade de São Paulo (2016); Universidade Federal do Amazonas (2016); Universidade Federal do Ceará (2016); Universidade Federal do Cariri (2016); Universidade Federal do Espírito Santo (2016); Universidade Federal do Estado do Rio de Janeiro (2016); Universidade Federal do Maranhão (2016); Universidade Federal do Pará (2016); Universidade Federal do Paraná (2016); Universidade Federal do Rio de Janeiro (2016); Universidade Federal do Rio Grande (2016); Universidade Federal do Rio Grande do Norte (2016); Universidade Federal do Rio Grande do Sul (2016); Universidade Federal Fluminense (2016).

Lembramos que as disciplinas foram classificadas como de "fundamentação" ou não pela sua nomenclatura inicial, e suas variações, como já mencionado antes. Observamos que a maioria dos cursos tem apenas entre 2 e 5 disciplinas de "fundamentação", incluindo aquelas de fundamentos da Biblioteconomia,.

Algumas instituições possuem disciplinas de fundamentação em pesquisa científica (USP, UFSCar e UFCA). No âmbito das habilidades profissionais, também podemos mencionar as disciplinas dedicadas aos estudos educacionais das faculdades da PUC Campinas, da UFG e da UDESC. São cursos de bacharelado, e não de licenciatura (a fim de preparar professores ou técnicos), mas a importância da preparação do profissional bibliotecário para o 
papel educador dentro de sua função é claramente reconhecida através dessa construção curricular.

Outro indicador relevante é o caso de alguns cursos - UFMA, USP Campus Ribeirão Preto e UFBA -, que apresentam disciplinas de fundamentação em linguística. Ainda, outra característica forte que podemos identificar é a presença de disciplinas de fundamentação no âmbito tecnológico, foco em informática e/ou computação. Os cursos da UFAL, UNESP, UFRN, UFSCar, UFMG, UFC e UnB possuem tais disciplinas, formando um grupo de três instituições ao sudeste (São Paulo e Minas Gerais), três no nordeste (Alagoas e Ceará) e uma da região centro-oeste (Brasília - DF) que abordam a temática.

Destacamos também mais alguns casos que chamaram a atenção nessa breve análise. A UFRGS possui duas disciplinas de fundamentação/introdução à ciência da informação, mas não possui nenhuma com a temática da Biblioteconomia (o discurso identitário sobre o conceito) - por isso selecionamos as duas primeiras disciplinas como alternativa de análise. Infelizmente não conseguimos, à época, o acesso às ementas, o que poderia nos esclarecer a relação de conceitualidade de tais disciplinas.

Outra particularidade observada está nas semelhanças entre as abordagens dos cursos da UFRJ e da FAINC. A primeira, a partir da nomenclatura do curso, adota a direção discursiva da área da gestão, e a percepção se confirma ao observarmos sua matriz, onde se encontra um grupo considerável de disciplinas de administração caracterizadas como obrigatórias. Notamos a semelhança com a FAINC quando observamos a matriz desta segunda, e vimos que o curso possui várias disciplinas voltadas especificamente para o domínio citado.

Uma última característica observada a respeito das disciplinas é o fato de que a UNIFOR não possui nenhuma disciplina de fundamentação, nem mesmo de Biblioteconomia, além de não possuir nenhuma disciplina que pudesse ser enquadrada como alternativa de análise para as observações anteriores. Reconhecemos, nesse caso, assim como nos demais, que a aproximação 
panorâmica, no plano morfológico, nas noções que se candidatam a macroconceito nas matrizes curriculares, não necessariamente evidenciam o plano epistemológico e uma discussão filosófica sobre a fundamentação de determinado domínio ou ciência. Assim, fica clara, aqui, a dificuldade, segundo esse ponto de observação, de determinar a profundidade pretendida por disciplinas como "introdução" ou "fundamentos" da computação. Essa etapa do estudo nos permite, pois, apenas reunir os primeiros indícios de questões ainda extremamente complexas e de difícil demarcação crítica no plano epistemológico do campo.

A Tabela 6 apresenta as relações de porcentagem referentes aos dados anteriores, mapa esse que nos indica qual a distribuição de disciplinas de fundamentação em relação ao total de disciplinas da matriz curricular de cada curso.

Tabela 6 - Porcentagem de disciplinas de fundamentação em relação ao total de disciplinas da matriz

\begin{tabular}{l|c}
\hline \multicolumn{1}{c|}{ INSTITUIÇÃO } & PORCENTAGEM \\
\hline FESPSP & $21,27 \%$ \\
\hline UnB & $21,21 \%$ \\
\hline UFC & $16,66 \%$ \\
\hline UFPR & $15,68 \%$ \\
\hline UFBA & $18,18 \%$ \\
\hline UFCA & $14,28 \%$ \\
\hline UFMG & $14,28 \%$ \\
\hline FURG & $13,63 \%$ \\
\hline USP & $12,12 \%$ \\
\hline UNIRIO - Bacharelado & $12 \%$ \\
\hline UFRJ & $11,76 \%$ \\
\hline UFRGS & $11,76 \%$ \\
\hline
\end{tabular}




\begin{tabular}{|c|c|}
\hline USP - Campus Ribeirão Preto & $11,42 \%$ \\
\hline UNIRIO - Licenciatura & $11,11 \%$ \\
\hline UFSCar & $9,09 \%$ \\
\hline UFPB & $7,89 \%$ \\
\hline UFAM & $7,89 \%$ \\
\hline UNIFAI & $7,69 \%$ \\
\hline UFF & $7,69 \%$ \\
\hline UFRN & $7,31 \%$ \\
\hline UFG & $6,81 \%$ \\
\hline UNESP & $6,97 \%$ \\
\hline UDESC & $6,66 \%$ \\
\hline UFPE & $6,25 \%$ \\
\hline UFSC & $5,55 \%$ \\
\hline UFES & $5,55 \%$ \\
\hline UFAL & $5,26 \%$ \\
\hline UFMA & $4,44 \%$ \\
\hline UEL & $4,08 \%$ \\
\hline PUC Campinas & $3,27 \%$ \\
\hline UFPA & $2,85 \%$ \\
\hline UNIFOR & $0 \%$ \\
\hline FAINC & $0 \%$ \\
\hline
\end{tabular}

Fonte: Centro Universitário Assunção (2016); Centro Universitário de Formiga (2016); Faculdades Integradas Coração de Jesus (2016); Fundação Escola de Sociologia e Política de São Paulo (2016); Instituto de Ensino Superior da Funlec (2016); Pontifícia Universidade Católica de Campinas (2016); Universidade de Brasília (2016); Universidade de São Paulo (2016); Universidade Estadual de Londrina (2016); Universidade Estadual Paulista (2016); Universidade Federal da Bahia (2016); Universidade Federal da Paraíba (2016); Universidade Federal de Alagoas (2016); Universidade Federal de Goiás (2016); Universidade Federal de Minas Gerais (2016); Universidade Federal de Pernambuco (2016); Universidade Federal de Santa Catarina (2016); Universidade Federal de São Carlos (2016); Universidade de São Paulo (2016); Universidade Federal do Amazonas (2016); Universidade Federal do Ceará (2016); Universidade Federal do Cariri (2016); Universidade Federal do Espírito Santo (2016); Universidade Federal do Estado do Rio de Janeiro (2016); Universidade Federal do Maranhão (2016); Universidade Federal do Pará (2016); Universidade Federal do Paraná (2016); Universidade Federal do Rio de Janeiro (2016); Universidade Federal do Rio Grande (2016); 
Universidade Federal do Rio Grande do Norte (2016); Universidade Federal do Rio Grande do Sul (2016); Universidade Federal Fluminense (2016).

Com o "mapa quantitativo" acima, encontramos a perspectiva da proporcionalidade de diferenças da quantidade de disciplinas de fundamentação que há em cada curso. A Tabela 5 identificou e relacionou as instituições por ordem crescente, de acordo com o número de disciplinas de fundamentação, enquanto a tabela anterior indica a porcentagem, mostrando que o curso que possui mais disciplinas de fundamentação não necessariamente está em vantagem nessa questão em relação aos outros cursos. Por exemplo, a UFPR que é a segunda instituição com maior número de disciplinas de fundamentos/introdução, ficando atrás da UnB, que é a terceira, pois a UFPR possui 51 disciplinas totais na matriz, enquanto a UnB, 33. Também é o caso do curso de bacharelado da UNIRIO, que possui 6 disciplinas de fundamentação assim como as anteriores - UFCA, UFC, UFBA, FURG e UFMG - mas a porcentagem é bastante inferior, devido ao número total de componentes curriculares.

No plano das autoridades bibliográficas, realizamos uma listagem completa com os autores e suas respectivas fontes incluídas nos planos de estudo das disciplinas. Ao todo, 216 autores foram identificados, sendo a distribuição quantitativa a seguinte:

Tabela 7 - Número de ocorrências de autoridades bibliográficas nos planos de estudo das disciplinas de fundamentação biblioteconômico-informacional

\begin{tabular}{l|c}
\multicolumn{1}{c|}{ Autoridades bibliográficas } & Ocorrências \\
\hline $\begin{array}{l}\text { FONSECA, Edson Nery da } \\
\text { VALENTIM, Marta L P }\end{array}$ & 10 \\
\hline SOUZA, Francisco das Chagas & 9 \\
\hline LE COADIC, Yves F & 8 \\
ROBREDO JAIME & 7 \\
\hline OLIVEIRA, Marlene & 6 \\
\hline DIAS, Eduardo Wense & 6 \\
\hline
\end{tabular}




\begin{tabular}{l|l}
\hline McGARRY, K & \\
MILANESI, & \\
ORTEGA, Cristina Dotta & \\
SARACEVIC, Tefko & \\
SMIT, J & \\
\hline
\end{tabular}

Fonte: Centro Universitário Assunção (2016); Centro Universitário de Formiga (2016); Faculdades Integradas Coração de Jesus (2016); Fundação Escola de Sociologia e Política de São Paulo (2016); Instituto de Ensino Superior da Funlec (2016); Pontifícia Universidade Católica De Campinas (2016); Universidade de Brasília (2016); Universidade de São Paulo (2016); Universidade Estadual de Londrina (2016); Universidade Estadual Paulista (2016); Universidade Federal da Bahia (2016); Universidade Federal da Paraíba (2016); Universidade Federal de Alagoas (2016); Universidade Federal de Goiás (2016); Universidade Federal de Minas Gerais (2016); Universidade Federal de Pernambuco (2016); Universidade Federal de Santa Catarina (2016); Universidade Federal de São Carlos (2016); Universidade de São Paulo (2016); universidade federal do amazonas (2016); universidade federal do ceará (2016); Universidade Federal do Cariri (2016); Universidade Federal do Espírito Santo (2016); Universidade Federal do Estado do Rio de Janeiro (2016); Universidade Federal do Maranhão (2016); Universidade Federal do Pará (2016); Universidade Federal do Paraná (2016); Universidade Federal do Rio de Janeiro (2016); Universidade Federal do Rio Grande (2016); Universidade Federal do Rio Grande do Norte (2016); Universidade Federal do Rio Grande do Sul (2016); Universidade Federal Fluminense (2016).

As autoridades destacadas pela ocorrência nos planos de estudo são basicamente pelas mesmas instituições, como, por exemplo, UFMG, UEL, USP, UFSCAR, UNESP e USFC, demarcando uma concentração na região sudeste do aprofundamento teórico no campo da fundamentação. O reconhecimento do perfil indica uma relação com tentativas de constituição de argumentos de fundamentação e obras funcionais (do ponto de vista mais histórico do que epistemológico). É possível observar, pela trajetória dos pesquisadores identificados e pelas fontes consultadas, que existe uma multiplicidade não apenas nas potencialidades de fundamentação, bem como nas formações e direções para além do debate epistemológico-histórico na formação do pensamento de tais autores.

Como vimos através do trabalho de Solange Mostafa (1985), a discussão sobre a produção científica no campo é recorrente, e a essa altura poderia ser, de alguma maneira, menos "enigmática". Já foi destacada a menção pelos autores anteriormente citados sobre a questão da falta de equilíbrio entre disciplinas chamadas "técnicas" e aquelas ditas "filosóficas", como sendo um dos motivos do déficit de novas teorias, metodologias e produções na área. 
O escopo final da compreensão a partir do corpus aponta para, no plano da fundamentação biblioteconômico-informacional, o desenvolvimento de um núcleo de afirmação epistemológica a partir da representação dos conceitos. A Tabela 4 demonstra, segundo as ocorrências conceituais, a esperada prioridade para macro-conceitos disciplinares, como Biblioteconomia, Ciência da Informação, Documentação, com destaque ainda para a demarcação do sujeito profissional, a partir do conceito Bibliotecário, e da institucionalidade vinculada ao fazer no campo, a partir do conceito Biblioteca.

Merecem atenção, ainda, nessa afirmação epistemológica, a prioridade dada nas matrizes dos conceitos Mercado de Trabalho, Profissional da Informação, Legislação \& Aspectos Legais, o que mais uma vez reforça a relação entre o núcleo epistemológico e a práxis informacional na fundamentação do campo. Reconhece-se, pois, no plano da incidência dos conceitos, a ausência de uma expressão conceitual propriamente epistemológica e crítico-social, apesar de tais ocorrências existirem em diferentes contextos nas matrizes do corpus, como demonstrado no Quadro 2.

\section{Considerações finais}

$\mathrm{Na}$ primeira análise do material coletado, ainda durante o processo de sistematização dos dados, levando em consideração as informações adquiridas através dos contatos, foi possível observar que os afastamentos na conceituação e na padronização entre matrizes curriculares, ementas e planos de estudo refletiram em dificuldade de cruzamento e comparação.

As ementas, portadoras de maior conjunto de elementos conceituais passíveis de investigação, representaram os dados com maior ausência de harmonia entre as instituições. Além disso, as particularidades do modo de apresentação de cada ementa geraram dificuldade de reconhecimento do papel dos termos e dos conceitos tratados como focos de cada disciplina.

Outra dificuldade central, além das disparidades entre a "discursividade" das ementas, foi a ausência de um "modelo de fundamentação" da CI no Brasil a 
partir de disciplinas dedicadas ao aspecto filosófico de identificação e reflexão sobre o campo informacional em sua amplitude teórico-metodológica. Ou seja, a padronização do ensino e saberes biblioteconômicos da qual fala Castro (2000), em um dos subtítulos do capítulo 5 de sua obra, se perdeu.

Reconhecemos que o estudo se deu em um contexto de amplas transformações na construção da experiência teórico-institucional no campo. É o exemplo citado do desenvolvimento dos cursos de Arquivologia e Museologia em paisagens antes demarcadas pelas formações de pós-graduação e de graduação em Biblioteconomia e Ciência da Informação. As transformações políticas e epistemológicas, logo, carecem de permanente revisão, cada vez mais vertical e qualitativa, na atualidade.

A inexistência de disciplinas correlatas (ou semelhantes) - e, em alguns casos, a inexistência objetiva de uma disciplina de fundamentos - resultava, naturalmente, na impossibilidade de aprofundar a reflexão comparada, que permitiria a passagem do estudo da ementa para o estudo dos planos de estudo (o que, por sua vez, nos levaria, por exemplo, ao reconhecimento de autores e obras influentes no campo).

Além dos percalços pontualmente relatados na coleta e sistematização dos dados, o estudo identificou a dificuldade de cruzamento de dados em razão de:

a) incompatibilidade de matrizes curriculares;

b) redundância de termos;

c) ausência de equilíbrio entre especificidade e generalidade dos conceitos ou expressões que representam os nomes das disciplinas.

Como identificado, não sendo nosso intuito uma discussão epistemológica sintética sobre a configuração das disciplinas, sua preocupação em sustentar, a partir da filosofia da ciência, os argumentos de constituição de uma racionalidade biblioteconômico-informacional, percebe-se, pela aproximação e pelo manejo da documentação da pesquisa, o distanciamento ainda flagrante de um debate sobre o modo específico como observamos o real a 
partir de aportes filosóficos. A teoria do conhecimento e suas múltiplas possibilidades de interpretação da realidade ainda parecem distantes de uma perspectiva de formação no contexto da graduação.

\section{Financiamento}

$\mathrm{O}$ artigo é fruto de pesquisa financiada pelo Conselho Nacional de Desenvolvimento Científico e Tecnológico (CNPq) e pela Fundação Carlos Chagas de Amparo à Pesquisa do Estado do Rio de Janeiro (FAPERJ).

\section{Referências}

ABECIN. [Portal eletrônico]. 2016. Disponível em:

<http://www.abecin.org.br/.>. Acesso em: 30 mar. 2016.

ANDRADE, Ana Maria C.; METCHEKO, Dulce M. B.; SOLLA, Sheila R. de C. Algumas considerações acerca da situação epistemológica da Biblioteconomia. Revista da Escola de Biblioteconomia da UFMG, Belo Horizonte, v. 10, n. 2, p. 153-162, set. 1981.

BROOKES, Bertram C. The foundations of information science. Part I. Philosophical aspects. Journal of Information Science, London,v. 2, p. 125133, 1980a.

BROOKES, Bertram C. The foundations of information science. Part II. Quantitative aspects: classes of things and the challenge of human individuality. Journal of Information Science, London, v. 2, p. 209-221, 1980 b.

BROOKES, Bertram C. The foundations of information science. Part III. Quantitative aspects: objective maps and subjective landscapes. Journal of Information Science, London,v. 2, p. 269-275, 1980c.

BROOKES, Bertram C. The foundations of information science. Part IV. Information science: the changing paradigm. Journal of Infomation Science, London, v. 3, p. 3-12, 1981.

CASTRO, César. História da biblioteconomia brasileira: perspectiva histórica. Brasília: Thesaurus, 2000.

CENTRO UNIVERSITÁRIO ASSUNÇÃO. [Portal eletrônico]. 2016.

Disponível em: < http://www.unifai.edu.br/>. Acesso em: 30 mar. 2016. 
CENTRO UNIVERSITÁRIO DE FORMIGA. [Portal eletrônico]. 2016.

Disponível em: < https://www.uniformg.edu.br/>. Acesso em: 30 mar. 2016.

COUZINET, Viviane. Transmitir, difundir: formas de institucionalização de uma disciplina. Perspectivas em Ciência da Informação, Belo Horizonte, 14, n. especial, p. 5-18, 2009.

FACULDADES INTEGRADAS CORAÇÃO DE JESUS. [Portal eletrônico]. 2016. Disponível em: <http://www.fainc.com.br/>. Acesso em: 30 mar. 2016.

FONSECA, Edson Nery da. Ciência da Informação e prática bibliotecária.

Ciência da Informação, Brasília, v. 16, n. 2, p. 125-127, jul./dez. 1987.

FONSECA, Edson Nery da. Introdução à Biblioteconomia. 2. ed. Brasília:

Briquet de Lemos, 2007.

FUNDAÇÃO ESCOLA DE SOCIOLOGIA E POLÍTICA DE SÃO PAULO.

[Portal eletrônico]. 2016. Disponível em: <www.fespsp.org.br/>. Acesso em: 30 mar. 2016.

GARCÍA GUTIÉRREZ, Antonio. Epistemología de la documentación. Barcelona: Editorial Stonberg, 2011.

INSTITUTO DE ENSINO SUPERIOR DA FUNLEC. [Portal eletrônico]. 2016. Disponível em: < http://www.iesf.funlec.com.br/>. Acesso em: 30 mar. 2016.

MIRANDA, Antonio. Ciência da Informação: teoria e metodologia de uma área em expansão. Brasília: Tesaurus, 2003.

MOSTAFA, Solange P. A produção de conhecimentos em Biblioteconomia. R. Biblioteconomia Brasília, Brasília, v. 11, n. 2, p. 221-229, jul./dez. 1983.

MOSTAFA, Solange Puntel. Epistemologia da Biblioteconomia. 1985. Tese (Doutorado em Educação) - Pontifícia Universidade Católica de São Paulo, São Paulo, 1985.

MUELLER, Suzana Pinheiro Machado. O ensino de Biblioteconomia no Brasil. Ciência da Informação, Brasília, v. 14, n. 1, p. 3-15, jan./jun. 1985.

PINHEIRO, Lena Vania Ribeiro; LOUREIRO, José Mauro Mateus. Traçados e limites da ciência da informação. Ciência da Informação, Brasília, v. 24, n. 1, p. 42-53, jan./abr. 1995.

PONTIFÍCIA UNIVERSIDADE CATÓLICA DE CAMPINAS. [Portal eletrônico]. 2016. Disponível em: < https://www.puc-

campinas.edu.br/>.Acesso em: 30 mar. 2016. 
ODDONE, Nanci. O IBBD e a informação científica: uma perspectiva histórica para a ciência da informação no Brasil. Ciência da Informação, Brasília, v. 35, n. 1, p. 45-56, jan./abr. 2006.

OTLET, Paul. Traité de documentation: le livre sur le livre: théorie et pratique. Brussels: Editiones Mundaneum, 1934.

RUSSO, Mariza. Fundamentos de Biblioteconomia e Ciência da Informação. Rio de Janeiro: E-papers Serviços Editoriais, 2010.

SHERA, J. H.; CLEVELAND, D. B. History and foundations of information science. Annual Review of Information Science and Technology, Maryland, v. 12, p. 249-275, 1977.

SILVA, Armando Malheiro da; RIBEIRO, Fernanda. Das ciências documentais à ciência da informação: ensaio epistemológico para um novo modelo curricular. Porto: Edições Afrontamento, 2002.

SOUZA, Francisco das Chagas de. Os paradigmas da Biblioteconomia e suas implicações no ensino desta ciência. Encontros Bibli, Florianópolis, v. 1, n. 2, 1996.

SOUZA, Francisco das Chagas de. Em busca de outra estrutura de educação bibliotecária para o Brasil. Informação e Sociedade, João Pessoa, v. 5, n. 1, p. 18-21, jan./dez. 1995.

SOUZA, Francisco das Chagas de. Ensino de Biblioteconomia no Brasil: o modelo norte-americano. Informação e Sociedade, João Pessoa, v. 3, n. 1, p. 16-19, jan./dez. 1993.

UNIVERSIDADE DE BRASÍLIA. [Portal eletrônico]. 2016. Disponível em: <www.unb.br/>. Acesso em: 30 mar. 2016.

UNIVERSIDADE DE SÃO PAULO. [Portal eletrônico]. 2016. Disponível em: < http://www5.usp.br/>. Acesso em: 30 mar. 2016.

UNIVERSIDADE ESTADUAL DE LONDRINA. [Portal eletrônico]. 2016. Disponível em: <www.uel.br/>. Acesso em: 30 mar. 2016.

UNIVERSIDADE ESTADUAL PAULISTA. [Portal eletrônico]. 2016. Disponível em: < http://www.unesp.br/>. Acesso em: 30 mar. 2016.

UNIVERSIDADE FEDERAL DA BAHIA. [Portal eletrônico]. 2016. Disponível em: <https://www.ufba.br/>. Acesso em: 30 mar. 2016.

UNIVERSIDADE FEDERAL DA PARAÍBA. [Portal eletrônico]. 2016. Disponível em: <www.ufpb.br/>. Acesso em: 30 mar. 2016. 
UNIVERSIDADE FEDERAL DE ALAGOAS. [Portal eletrônico]. 2016.

Disponível em: <www.ufal.edu.br/>. Acesso em: 30 mar. 2016.

UNIVERSIDADE FEDERAL DE GOIÁS. [Portal eletrônico]. 2016.

Disponível em: <https://www.ufg.br/>. Acesso em: 30 mar. 2016.

UNIVERSIDADE FEDERAL DE MINAS GERAIS. [Portal eletrônico]. 2016. Disponível em: <https://ufmg.br/>. Acesso em: 30 mar. 2016.

UNIVERSIDADE FEDERAL DE PERNAMBUCO. [Portal eletrônico]. 2016. Disponível em: < https://www.ufpe.br/ >. Acesso em: 30 mar. 2016.

UNIVERSIDADE FEDERAL DE SANTA CATARINA. [Portal eletrônico]. 2016. Disponível em: <https://ufsc.br/ > . Acesso em: 30 mar. 2016.

UNIVERSIDADE FEDERAL DE SÃO CARLOS. [Portal eletrônico]. 2016. Disponível em: < http://www2.ufscar.br/>. Acesso em: 30 mar. 2016.

UNIVERSIDADE DE SÃO PAULO. Ribeirão Preto. [Portal eletrônico]. 2016. Disponível em: <www.ribeirao.usp.br/>. Acesso em: 30 mar. 2016.

UNIVERSIDADE FEDERAL DO AMAZONAS. [Portal eletrônico]. 2016. Disponível em: <www.ufam.edu.br/>. Acesso em: 30 mar. 2016.

UNIVERSIDADE FEDERAL DO CEARÁ. [Portal eletrônico]. 2016. Disponível em: <www.ufc.br/>. Acesso em: 30 mar. 2016.

UNIVERSIDADE FEDERAL DO CARIRI. [Portal eletrônico]. 2016. Disponível em: < https://www.ufca.edu.br/ > . Acesso em: 30 mar. 2016.

UNIVERSIDADE FEDERAL DO ESPÍRITO SANTO. [Portal eletrônico]. 2016. Disponível em: < www.ufes.br/>. Acesso em: 30 mar. 2016.

UNIVERSIDADE FEDERAL DO ESTADO DO RIO DE JANEIRO. [Portal eletrônico]. 2016. Disponível em: <http://www.unirio.br/>. Acesso em: 30 mar. 2016.

UNIVERSIDADE FEDERAL DO MARANHÃO. [Portal eletrônico]. 2016. Disponível em: <www.ufma.br/>. Acesso em: 30 mar. 2016.

UNIVERSIDADE FEDERAL DO PARÁ. [Portal eletrônico]. 2016. Disponível em: <https://portal.ufpa.br/>. Acesso em: 30 mar. 2016.

UNIVERSIDADE FEDERAL DO PARANÁ. [Portal eletrônico]. 2016. Disponível em: <www.ufpr.br/>. Acesso em: 30 mar. 2016.

UNIVERSIDADE FEDERAL DO RIO DE JANEIRO. [Portal eletrônico]. 2016. Disponível em: <https://ufrj.br/>. Acesso em: 30 mar. 2016. 
UNIVERSIDADE FEDERAL DO RIO GRANDE. [Portal eletrônico]. 2016.

Disponível em: < https://www.furg.br/>. Acesso em: 30 mar. 2016.

UNIVERSIDADE FEDERAL DO RIO GRANDE DO NORTE. [Portal

eletrônico]. 2016. Disponível em: <www.ufrn.br/>. Acesso em: 30 mar. 2016.

UNIVERSIDADE FEDERAL DO RIO GRANDE DO SUL. [Portal

eletrônico]. 2016. Disponível em: < www.ufrgs.br/ > . Acesso em: 30 mar. 2016.

UNIVERSIDADE FEDERAL FLUMINENSE. [Portal eletrônico]. 2016. Disponível em: <www.uff.br/>. Acesso em: 30 mar. 2016.

\title{
The construction of the library and information science
}

\section{foundations in Brazilian undergradute courses}

\begin{abstract}
This paper intended to discuss the library and information science epistemology in Brazil, from a documentary perspective, structured on the analysis of curricular matrices, syllabus and programs. Our general objective was to understand the construction of the theoretical foundations of the field, starting from the disciplines which the focus was on the foundation of Brazilian undergraduate courses. As specific objectives, we aimed at: A. discussing the qualitative and quantitative condition of the foundation in Librarianship \& Information Science in Brazil today; B. identifying the central concepts of the librarian-informational basis from course syllabus; C. to map the bibliographic authorities present in such a foundation from the bibliographic references of the programs; D. mapping the central bibliographic sources present from the bibliographic references of the programs. The methodological procedures went from the collection stage of materials (matrices, menus and programs) in the electronic portals of the universities and direct requests, to the analysis and discussion of the data, with the creation of comparative tables. At the end of the paper, the heterogeneity of the processes of library and information science foundations in the country was clear, as well as raising several hypotheses for further study in future studies.
\end{abstract}

Keywords: Library and Information Science - Brazil. Epistemology. Teaching. curricular structure. Library and Information Science foundations.

Recebido: 27/07/2017

Aceito: $18 / 10 / 2017$ 